\title{
Implementation of a physically based water percolation routine in the Crocus/SURFEX (V7.3) snowpack model
}

\author{
Christopher J. L. D’Amboise ${ }^{1,2}$, Karsten Müller ${ }^{1}$, Laurent Oxarango ${ }^{3}$, Samuel Morin ${ }^{4}$, and Thomas V. Schuler ${ }^{2}$ \\ ${ }^{1}$ Norwegian Water Resources and Energy Directorate, Oslo, 0368, Norway \\ ${ }^{2}$ Department of Geoscience, University of Oslo, Oslo, 0316, Norway \\ ${ }^{3}$ Univ. Grenoble Alpes, CNRS, IRD, IGE, 38000 Grenoble, France \\ ${ }^{4}$ Météo-France - CNRS, CNRM UMR 3589, Centre d'Etudes de la Neige, Grenoble, France \\ Correspondence to: Christopher J. L. D’Amboise (chda@ nve.no)
}

Received: 7 March 2017 - Discussion started: 10 April 2017

Revised: 14 August 2017 - Accepted: 18 August 2017 - Published: 26 September 2017

\begin{abstract}
We present a new water percolation routine added to the one-dimensional snowpack model Crocus as an alternative to the empirical bucket routine. This routine solves the Richards equation, which describes flow of water through unsaturated porous snow governed by capillary suction, gravity and hydraulic conductivity of the snow layers. We tested the Richards routine on two data sets, one recorded from an automatic weather station over the winter of 2013-2014 at Filefjell, Norway, and the other an idealized synthetic data set. Model results using the Richards routine generally lead to higher water contents in the snow layers. Snow layers often reached a point at which the ice crystals' surface area is completely covered by a thin film of water (the transition between pendular and funicular regimes), at which feedback from the snow metamorphism and compaction routines are expected to be nonlinear. With the synthetic simulation $18 \%$ of snow layers obtained a saturation of $>10 \%$ and $0.57 \%$ of layers reached saturation of $>15 \%$. The Richards routine had a maximum liquid water content of $173.6 \mathrm{~kg} \mathrm{~m}^{-3}$ whereas the bucket routine had a maximum of $42.1 \mathrm{~kg} \mathrm{~m}^{-3}$. We found that wet-snow processes, such as wet-snow metamorphism and wet-snow compaction rates, are not accurately represented at higher water contents. These routines feed back on the Richards routines, which rely heavily on grain size and snow density. The parameter sets for the water retention curve and hydraulic conductivity of snow layers, which are used in the Richards routine, do not represent all the snow types that can be found in a natural snowpack. We show that the new routine has been implemented in the Crocus model, but due to feedback amplification and parameter
\end{abstract}

uncertainties, meaningful applicability is limited. Updating or adapting other routines in Crocus, specifically the snow compaction routine and the grain metamorphism routine, is needed before Crocus can accurately simulate the snowpack using the Richards routine.

\section{Introduction}

Knowledge about the process of water percolation in the snowpack is necessary for improving many applications such as flood forecasting, river and reservoir management, slope stability, and avalanche forecasting. Measuring liquid water content (LWC) of snow layers is not practical because it is time consuming and LWC has the ability to dramatically change over the timescales that are considerable shorter than those of observations (Techel and Pielmeier, 2011; Wakahama, 1975). When water is introduced to a snowpack, snow stability is able to change rapidly, because cohesion strength depends on the amount of water saturation (Ambach and Howorka, 1966; Brun and Rey, 1987; Hartman and Borgeson, 2008). Because LWC of a snowpack can change quickly, avalanche forecasters, mountain guides, researchers and rescue workers have reported that they do not fully trust classical snow stability tests (e.g., Rutschblock and extended column tests) when performed in wet-snow (Techel and Pielmeier, 2009). To improve flood and avalanche forecasting capabilities, detailed snowpack hydraulic information on fine spatial and temporal scales is required. One way to achieve a detailed view of snow hydraulics is to supplement 
meteorological and hydrological observations with physically based percolation modeling. A physically based water percolation model has been used along with weather station data to improve forecasts of wet-snow stability (Wever et al., 2016a) and determine initial conditions for simulations of avalanche dynamics (Vera Valero et al., 2016).

Vertical water flow through a layered snowpack can occur in two different modes, matrix flow and preferential flow. Matrix flow is a diffusive flow through the pore space of the snowpack, which sets up a uniform water front. Preferential flow, also called finger flow, is when water quickly flows in channels to deeper layers (Marsh and Woo, 1984). A combination of both flow schemes occurs in a snow layer; often preferential flow will initiate wetting a dry snow layer, followed by an expansion of flow paths that will end up in matrix flow (Williams et al., 2010). As water percolates through an isothermal snowpack, preferential flow paths are created, and water transport through the snowpack becomes very efficient (Colbeck, 1979). Using multicolored dye tracer experiments, Schneebeli (1995) has shown that the preferential flow channels in an isothermal snowpack can migrate over time.

Gravity and capillary forces govern water movement in unsaturated snow (Colbeck, 1972; Jordan et al., 1999). Capillary forces arise from adhesion and surface tension of liquid water inside the pore space of the snowpack. Snow layering produces vertical gradients since capillary pressure has an inverse relationship to pore size (Wankiewicz, 1978). Pressure gradients acting against gravity may induce the formation of preferential flow channels, as flow channels in soil occur where capillary pressure gradient opposes the water flow direction (Philip, 1975). Two common textural barriers are crust layers and neighboring snow layers with sharp grain size differences. Assessing the hydraulic conductivity of textural barriers is not straightforward, because layer behavior may vary greatly; for example, crusts can act as an impermeable layer or act similar to vertical conduits (Jordan, 1995). Fine-grained snow layered above coarser grains gives rise to flow barriers due to capillary pressure gradients opposing gravity. An area of high saturation can be found above such barriers and lateral water flow due to suction, terrain slope and water pooling is a common result (Colbeck, 1974b; Williams et al., 2010).

Physically based models of water percolation through snow were first developed to describe gravitationally driven flow through isotropic isothermal snow, neglecting capillary effects (Colbeck, 1972). Model complexity evolved and snow layering was introduced (Colbeck, 1974b, 1975), as well as heterogeneous flow where water is routed to deeper layers via flow channels (Colbeck, 1979). Further improvement in modeling percolation in cold snowpacks was addressed by including thermodynamics into percolation models (Bengtsson, 1982; Colbeck, 1976; Illangasekare et al., 1990). Capillary forces were introduced in some early models despite the deficiency in parameter sets (Colbeck, 1974a;
Jordan, 1983; Wankiewicz, 1978). Wankiewicz (1978) concluded that more information on snow microstructure is needed to improve modeling of water percolation through a layered snowpack. Some recent models include gravity and suction-driven, preferential flow in isothermal snow layers (Hirashima et al., 2014; Katsushima et al., 2009).

Measuring the hydraulic conductivity and water retention of snow layers is a time-consuming task performed in a cold lab. It cannot currently be conducted in the field or even deployed as an autonomous recording system. Yet, new parameterizations of the retention curve (Yamaguchi et al., 2010, 2012) and permeability, which relates to hydraulic conductivity (Calonne et al., 2012), have been developed recently. These developments have been utilized in percolation models based on Darcy's law (Hirashima et al., 2010) and the Richards equation (Wever et al., 2014, 2015). Hydraulic conductivity and water retention of snow layers give insight into how the snowpack may evolve in regards to LWC. For instance, the 2012 surface runoff anomaly from the Greenland Ice Sheet can be explained by the reduced hydraulic conductivity of near-surface firn and ice layers. Growth of nearsurface ice layers prior to the 2012 melt season caused low hydraulic conductivity between surface layers and deep firn and ice layers. This effectively sealed off the available pore space in deep, cold firn which usually absorbed a large part of meltwater, thereby causing an increased amount of earlyseason runoff (Machguth et al., 2016). Although having important consequences, few models are capable of adequately simulating the formation of ice layers or lenses and their hydrological impact. A dual-domain Richards-based model has begun explaining preferential flow paths, which can reproduce some of the ice layers present in the snowpack (Wever et al., 2016b). The Richards equation, when applied to snow, describes water percolation through a porous ice matrix considering the water retention curve and the hydraulic conductivity of snow layers. A one-dimensional Richards equation solver was recently added to the detailed snow model SNOWPACK (Wever et al., 2014, 2015). We added a similar physical water transport routine to the snowpack model Crocus. This paper will discuss the parameterization, sensitivity of the new routine and compare difference in water percolation with the bucket routine for two data sets.

\section{SURFEX, ISBA and Crocus description}

Crocus is a standalone snowpack model, although Crocus is often run coupled to the SURFEX and ISBA models for dynamic boundary conditions at the snow-atmosphere and snow-ground interfaces. SURFEX is an atmosphere to surface coupling model, with ISBA (Interactions between Soil, Biosphere, and Atmosphere) being the land surface scheme (Noilhan and Mahfouf, 1996). The Crocus model (Brun et al., 1989) is the most detailed of three snowpack models embedded in the ISBA routine. It was classified in the group 


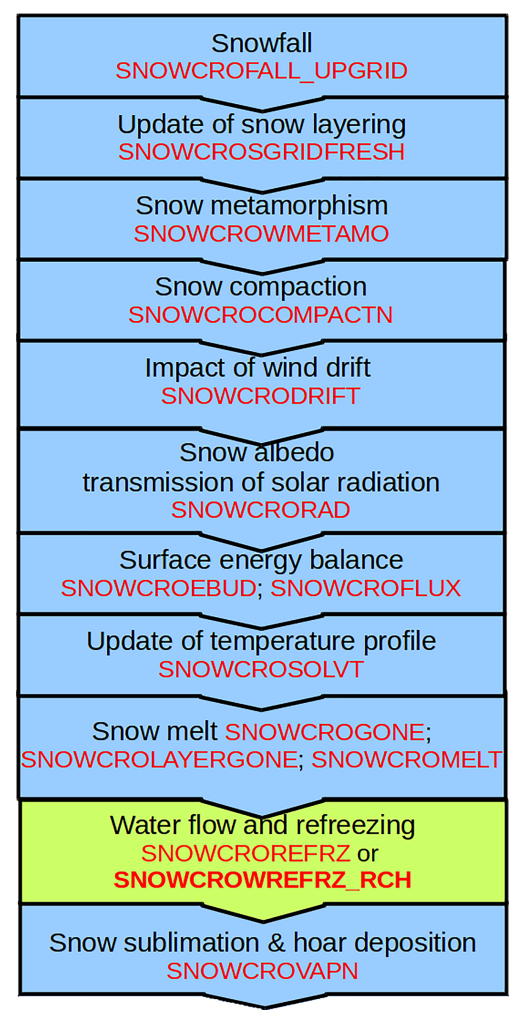

Figure 1. Routines in the Crocus snowpack model with the water percolation routines highlighted in green.

of "most complex snow models" by the Snow Models intercomparison project (Etchevers et al., 2004). Crocus is a one-dimensional multilayer model that describes the snow microstructure evolution based on environmental conditions. This model simulates the snowpack from the first snow to melt out, by calculating mass and energy fluxes between snow layers and its interface with the underlying ground and overlying atmosphere. Processes that act on and in the snowpack are summarized in Vionnet et al. (2012), which are represented in Crocus by routines (shown in Fig. 1). These routines run in a sequential manner. This paper will discuss a new option for the water percolation routine for the Crocus model but does not consider aspects of coupling between Crocus and other components in ISBA and SURFEX. For a detailed description of the implementation of Crocus in SURFEX and a detailed description of Crocus see Vionnet et al. (2012).

The SURFEX/ISBA-Crocus default time step is $15 \mathrm{~min}$, denoted as $T_{\text {Crocus }}$, but in this study, $T_{\text {Crocus }}$ will be varied to examine sensitivity. Crocus requires the following forcing variables: air temperature, humidity, wind speed, incoming shortwave and longwave radiation, solid and liquid precipitation rate, and atmospheric pressure (Vionnet et al., 2012). Forcing data are generally provided by highly instrumented test sites, output from numerical weather prediction models
(Vernay et al., 2015) or an assimilation or combination of the two (Durand et al., 2009).

The water transport and refreezing processes are expressed in the SNOWCROREFREZ routine (Fig. 1). Feedbacks exist between the liquid water transport (SNOWCROREFREZ) and other processes such as snow compaction (SNOWCROCOMPACTN) and metamorphism (SNOWCROMETAMO). It is important to realize that changes to the amount and timing of water percolation will feedback to other routines and affect other snowpack variables.

\section{The bucket approach}

To describe water percolation in snow, Crocus has historically used an empirically based routine, the so-called bucket routine that has been calibrated using long time series of lysimeter data (Morin et al., 2012) and drainage experiments on the irreducible water content (Coleou and Lesaffre, 1998). The bucket routine uses a holding capacity, defined by a percentage of the snow layer pore space. A snow layer's "bucket" is filled up with water when water is introduced via rain or melt. Once the bucket is full, overflow occurs to fill up the subsequent snow layer's bucket, restricting water motion in the downward direction. The "bucket size" or holding capacity has been defined as $5 \%$ of a layer's pore spaces as default, although this can be adapted if needed (Vionnet et al., 2012). For Crocus, the holding capacity is proportional to the density of the snow layer but is independent of snow grain type or surrounding environment (adjacent snow layers, soil, etc.). The size of the "buckets" is not agreed upon in the literature, which is discussed in detail in Lafaysse et al. (2017, Sect. 3.7). Singh et al. (1997) found water holding capacity to be $6.8 \%$ of a snow layer's volume (note this is total volume not just pore space). However, when an impermeable layer was set beneath it, the holding capacity rose to $14.2 \%$, showing that the surrounding environment has an effect on LWC of a snow layer, at least for a short time period.

\section{Implementation of the Richards routine in Crocus}

The Richards routine describes motion of water through an unsaturated porous matrix considering capillary-driven and gravity flow. Recent developments in parameterizing the conductivity of snow and snowpack water retention allow for the implementation of the Richards equation in layered snow pack models. In contrast to the bucket model, the Richards routine allows for upward motion of water if capillary pressure conditions are suitable.

A Richards solver has recently been implemented in the SNOWPACK model (Wever et al., 2014). A comparison between the bucket percolation and Richards percolation in the SNOWPACK model showed that the Richards routine performed better than the bucket routine for a subday timescale when compared to lysimeter data (Wever et al., 2014, 2015). 
However, Avanzi et al. (2016) found the speed of water transport with the Richards equation over a capillary barrier to be underestimated when compared to experimental results, but the model reproduces an increased LWC above barriers.

This paper discusses the implementation of a similar routine in the Crocus model. The new routine SNOWCROPERCO_RCH represents an alternative to the SNOWCROPERCO routine (bucket; Fig. 1). We use the snow layer discretization in Crocus as a mesh for solving the Richards equation.

Richards equation (Eq. 1) is a nonlinear partial differential equation describing the water mass balance of snow with water fluxes expressed using a generalized Darcy law, taking into account the dependence of hydraulic conductivity with water content. Its main variables are the pressure head $(h)$ and the volumetric liquid water content $(\theta)$.

$$
\frac{\partial \theta}{\partial t}=\frac{\partial}{\partial z}\left(K(\theta) \cdot \frac{\partial H}{\partial z}\right)
$$

$K(\theta)$ is the hydraulic conductivity which is a function of the volumetric water content $(\theta)$, and $t$ and $z$ denote time and depth (positive downward). $H$ is the hydraulic head, which is the sum of the pressure head $(h)$ and the elevation $(z)$, which is negative because $z$ is positive downward (Eq. 2).

$H=h-z$

The water retention curve and the hydraulic conductivity function need to be expressed for each snow layer.

\subsection{Water retention curve}

Using the Van Genuchten (1980) parameterization, the water retention curve can be expressed with Eq. (3) if four parameters $\left(\alpha, n, \theta_{\mathrm{r}}, \theta_{\mathrm{s}}\right)$ are known, where $\alpha$ and $n$ are the Van Genuchten fit parameters (see Eq. 4) and $\theta_{\mathrm{s}}$ (Eq. 5) and $\theta_{\mathrm{r}}$ (Eq. 7) are the saturated water content and the residual water content, respectively.

$\theta=\theta_{\mathrm{r}}+\left(\theta_{\mathrm{s}}-\theta_{\mathrm{r}}\right) \cdot\left(1+(\alpha \cdot h)^{n}\right)^{-\left(1-\frac{1}{n}\right)}$

Recent experiments (Yamaguchi et al., 2010, 2012) and theoretical estimates based on prior experiments (Daanen and Nieber, 2009) propose parameter sets for these four variables. This paper utilizes the Yamaguchi et al. (2012) parameter set (we also provide options in Crocus to use two alternative parameter sets, see Appendix B).

$\alpha=4.4 \times 10^{6} \cdot\left(\frac{\rho_{\text {snow }}}{D \cdot 1000}\right)^{-0.98}$

$n=1+2.7 \times 10^{3} \cdot\left(\frac{\rho_{\text {snow }}}{D \cdot 1000}\right)^{0.61}$

Here, $\rho_{\text {snow }}$ is the dry density of the snow, $D$ is grain size diameter and $P$ is porosity (volume of pore space).

$\theta_{\mathrm{s}}=0.9 \times P$
Yamaguchi et al. (2012) performed a drainage experiment to obtain the Van Genuchten fit parameters. The gravitational drainage experiment assumed the saturated hydraulic conductivity $\theta_{\mathrm{s}}$ for snow to be $90 \%$ of the pore spaces. This is due to small air bubbles that become trapped in the pores between the snow grains as the snow saturates. One should note that Yamaguchi's study examined samples of melt form and small rounded grains with a density range of $361-636 \mathrm{~kg} \mathrm{~m}^{-3}$ and grain size range of 0.05 to $5.8 \mathrm{~mm}$. Columns of snow were saturated with $0{ }^{\circ} \mathrm{C}$ water and left to drain. The study found a parameter set for melt-form crystals and concluded that rounded crystals could not be represented with the same parameter set as melt forms.

The Van Genuchten parameterization being applied is adopted from soil science for flow in an unsaturated soil matrix. The residual water content in snow presents specific challenges that are not present when applied to soil. Snow is often completely dry via phase transform, whereas soil is assumed to always have a small amount of liquid water. The term $\theta_{\mathrm{r}}$ is defined as the amount of water that remains in the porous medium with infinite suction being applied. It corresponds to disconnected water patches entrapped in the pore system. Following Yamaguchi et al. (2010), a residual water content $\theta_{\mathrm{r}}=0.02$ is adopted. However, the LWC of a snow sample can further "dry out" via evaporation and freezing, resulting in a negative saturation. $(S)$

$S=\frac{\theta-\theta_{\mathrm{r}}}{\theta_{\mathrm{s}}-\theta_{\mathrm{r}}}, \quad$ where $\theta_{\mathrm{r}}<\theta<\theta_{\mathrm{s}}$

Negative saturation (where $0 \leq \theta<\theta_{\mathrm{r}}$ ) is physically possible with phase change, but causes numerical problems. Therefore, saturation needs to be restricted between 0 and 1 . To overcome this limitation we use a continuous piecewise function to keep $\theta>\theta_{\mathrm{r}}$.

$\theta_{\mathrm{r}}= \begin{cases}0.02 & \text { if } \theta>0.02 \\ 0.75 \cdot \theta & \text { if } \theta \leq 0.02\end{cases}$

To avoid infinite values of the hydraulic head (Fig. 2) and hydraulic conductivity (Fig. 3, Sect. 3.2) of 0 when approaching $\mathrm{LWC}=0$, a small amount of water needs to be added to snow layers that are completely dry. Water is added to the dry layers such that all dry layers start with the same pressure head, which corresponds to a minimum pressure head needed to keep all dry layers $\leq \theta_{\min }$. In this study we call this added water "prewetting". The default value of $\theta_{\min }=10^{-5}$ (unitless) was adopted, although a sensitivity test varies the value of $\theta_{\min }$.

\subsection{Hydraulic conductivity}

Hydraulic conductivity $(K)$ is a function of water content $(\theta)$; see Eq. (8). As a snow layer gets wetter the conductivity will increase (Fig. 3).

$K(\theta)=k_{\mathrm{r}}(\theta) \cdot K_{\text {sat }}\left(D, \rho_{\text {snow }}\right)$ 


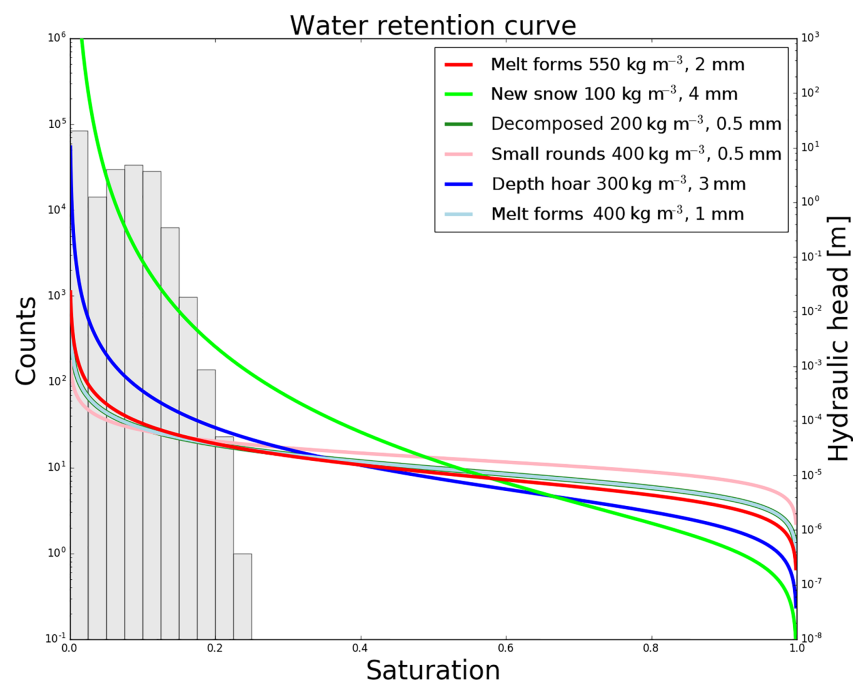

Figure 2. Water retention curve using Yamaguchi et al. (2012) in the Van Genuchten (1980) parameterization. Typical values for density and grain sizes of different snow crystals or grains were chosen to show hydraulic head as a function of saturation for different snow layers that it is applied to in the Richards routine. The density and grain size values were chosen from each crystal type from within a reasonable range that may be found in nature. Background shows a histogram of the simulated data sets' saturation with a $T_{\text {Crocus }}=$ 900 s time step before entering the Richards routine (left $y$ axis).

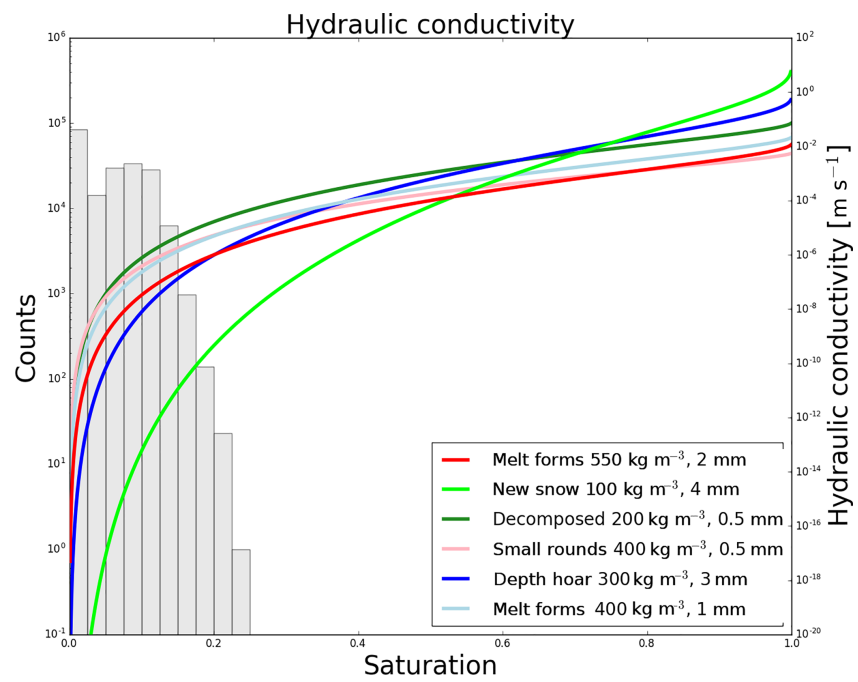

Figure 3. Hydraulic conductivity curve derived from Calonne et al. (2012) using Yamaguchi et al. (2012) parameters. Typical values for density and grain sizes of different snow crystals or grains were chosen to show the hydraulic conductivity for the spectrum of different snow layers that it is applied to in the Richards routine. The density and grain size values were chosen from each crystal type from within a reasonable range that may be found in nature. Background shows a histogram of the simulated data sets' saturation with a $T_{\text {Crocus }}=900 \mathrm{~s}$ time step before entering the Richards routine (left $y$ axis).
The Van Genuchten-Mualem equation (Van Genuchten, 1980 and Eq. 9) is used to calculate the relative permeability $k_{\mathrm{r}}$. It is implemented as a function of $h$ (using Eq. 3 for the relation between $h$ and $\theta$ ):

$$
\begin{aligned}
k_{\mathrm{r}} & =\left(1+|\alpha \cdot h|^{\frac{1}{1-m}}\right)^{\frac{-m}{2}} \\
& \cdot\left(1-\left(1-\left(1+|\alpha \cdot h|^{\frac{1}{1-m}}\right)^{-1}\right)^{m}\right)^{2}
\end{aligned}
$$

where $m=1-1 / n$. Hydraulic conductivity reaches a maximum when the snow matrix is saturated, known as conductivity at saturation $\left(K_{\text {sat }}\right)$. Since conductivity at saturation is dictated by snow structure, which is a complex system, it is described by a simple statistical model in both parameter sets available. It should be noted that both $K_{\text {sat }}$ (Eq. 10) and $k_{\mathrm{r}}$ (Eq. 9 through $\alpha$ and $m$ ) are dependent on the dry density of the snow and the grain size.

Calonne et al. (2012) used three-dimensional images of the microstructure of snow to derive the permeability (conductivity) from different snow types and densities ranging from $<100 \mathrm{~kg} \mathrm{~m}^{-3}$ to $\sim 550 \mathrm{~kg} \mathrm{~m}^{-3}$, seen in Eq. (10). Equation (10) is the preferred parameter set due to the range of snow types and densities that went into deriving the equation (other alternatives are described in Appendix B).

$K_{\text {sat }}=3.0 \cdot\left(\frac{D}{2}\right)^{2} \cdot \exp \left(-0.013 \cdot \rho_{\text {snow }}\right) \cdot\left(\frac{G \cdot \rho_{\text {water }}}{\mu_{\text {water }}}\right)$

$G=9.816 \mathrm{~m} \mathrm{~s}^{-2}$ is the acceleration due to gravity, and $\mu_{\text {water }}=0.001792 \mathrm{~kg} \mathrm{~m}^{-1} \mathrm{~s}^{-1}$ is the dynamic viscosity of water at $0{ }^{\circ} \mathrm{C}$.

\subsection{Solving the Richards equation}

To reduce unnecessary computations, the following two conditions need to be satisfied before entering the Richards routine.

1. There must be a substantial snowpack: if there are fewer than three layers of snow the bucket model will be used for water percolation.

2. There must liquid water: $\theta<\theta_{\min }$, or the rain flux (over the time step of $15 \mathrm{~min})<10^{-10} \mathrm{~m}$.

If one of these two conditions are not satisfied Crocus will be run without calling the Richards routine.

To solve the Richards equation, we utilize the following strategy: a finite volume discretization is applied taking each snow layer as integration volume. The average pressure head of each snow layer (corresponding to its LWC) is supposed to apply in the center of the layer.

The water fluxes $(\Phi)$ are computed at the interface between layers. Counted positive when entering a snow layer, 
the flux at the top and the bottom are computed respectively as follows:

$$
\begin{aligned}
& \Phi_{i, \text { top }}^{t+1}=K_{\text {top }}^{t+1}\left(\theta_{i}^{t+1}, \theta_{i-1}^{t+1}\right)\left(\frac{h_{i-1}^{t+1}-h_{i}^{t+1}}{\Delta z_{\text {top }}}+1\right), \\
& \Phi_{i, \text { bot }}^{t+1}=K_{\text {bot }}^{t+1}\left(\theta_{i,}^{t+1}, \theta_{i+1}^{t+1}\right)\left(\frac{h_{i+1}^{t+1}-h_{i}^{t+1}}{\Delta z_{\text {bot }}}-1\right),
\end{aligned}
$$

where $i$ is the index for snow layer (layer 1 at top of the snow pack). Values on the interface between two snow layers are indicated with "top" and "bot" (bottom) subscript respectively.

$K_{\text {top }}$ and $K_{\text {bot }}$ are the hydraulic conductivity of the upper and lower boundary interfaces of layer $i$, respectively. To compute $K_{\text {top }}$ and $K_{\text {bot }}$ the arithmetic mean was used as an estimate of the conductivity at snow layer interfaces, shown in Eq. (12).

$$
\begin{aligned}
K_{\text {top }} & =\frac{K_{i} \cdot \Delta z_{i}+K_{i-1} \cdot \Delta z_{i-1}}{\Delta z_{i}+\Delta z_{i-1}} \\
K_{\text {bot }} & =\frac{K_{i} \cdot \Delta z_{i}+K_{i+1} \cdot \Delta z_{i+1}}{\Delta z_{i}+\Delta z_{i+1}}
\end{aligned}
$$

The terms $\Delta z_{\text {bot }}$ and $\Delta z_{\text {top }}$ are the distance between layer mid-points, as described below in Eq. (13).

$$
\Delta z_{\text {top }}=\frac{\Delta z_{i}+\Delta z_{i-1}}{2} \quad \Delta z_{\text {bot }}=\frac{\Delta z_{i}+\Delta z_{i+1}}{2}
$$

Averaging conductivity of two adjacent snow layers with a simple arithmetic mean as an estimate for the interface value may be over-simplifying the conductivity of snow. Snow grain size, density and crystal types often have sharply defined borders. These parameters would have great influence on the snow hydraulic conductivity. It could be argued that a piecewise function comprised of individual snow layers' conductivity better describes the vertical pattern of conductivity in the snow pack (Szymkiewicz, 2009). However, when a piecewise function was tested, "dry layers" (that needed prewetting) caused impermeable barriers and caused numerical problems for the simulation. Other options for combining conductivity values of snow layers to estimate the interface are possible, but more research is needed to understand how the interface conductivity behaves.

The time discretization is a Crank-Nicolson finite differences scheme, which is second-order accurate in time. The nonlinearity of the equation is then dealt with the iterative methodology proposed by Celia et al. (1990). It approximates $\theta_{i}^{t+1, k+1}$ by a truncated Taylor series:

$\theta_{i}^{t+1, k+1}=\theta_{i}^{t+1, k}+\left.\frac{\mathrm{d} \theta}{\mathrm{d} h}\right|_{i} ^{t+1, k}\left(h_{i}^{t+1, k+1}-h_{i}^{t+1, k}\right)$,

where the superscript $k$ refers to the evolution of the iterative process, and $\left.\frac{\mathrm{d} \theta}{\mathrm{d} h}\right|_{i} ^{t+1, k}$ is the derivative of the retention curve
(Eq. 3) computed analytically for $\theta_{i}^{t+1, k}$ (or $h_{i}^{t+1, k}$ ). The final discretized form of the Richards equation (Eq. 1) including the Crank-Nicolson scheme with Celia decomposition reads as follows:

$$
\begin{aligned}
& \frac{\theta_{i}^{t+1, k}+C_{h}^{t+1, k}\left(h_{i}^{t+1, k+1}-h_{i}^{t+1, k}\right)-\theta_{i}^{t}}{\Delta t} \Delta z_{i} \\
& \quad=0.5\left(\Phi_{i, \text { top }}^{t+1, k+1}+\Phi_{i, \text { bot }}^{t+1, k+1}\right)+0.5\left(\Phi_{i, \text { top }}^{t}+\Phi_{i, \text { bot }}^{t}\right)
\end{aligned}
$$

The system of discretized equations is solved with respect to the pressure head $h$ at iteration level $k+1$. The threediagonal linear system is solved with the direct LU Thomas algorithm. The value of the volumetric content is then updated until the convergence criterion of the Picard iterative process is reached (see Appendix A).

The Richards equation is solved on a variable time step denoted with a $\Delta t$ (see Appendix A for how time step varies). The SURFEX/Crocus model is run on a fixed time step $T_{\text {Crocus}}$, which is set to $15 \mathrm{~min}$ unless otherwise specified. Snow layer properties such as grain size and snow density and snow layer temperature are updated on each $T_{\text {Crocus }}$. The variable time step segments $T_{\text {Crocus }}$ up into smaller steps as needed, until $\Sigma \Delta t=T_{\text {Crocus }}$. Outflow to soil and liquid water content of each layer are updated in the main Crocus routine when the time steps join. Finally, density, snow temperature and liquid water content are updated and the Crocus routine is finished.

\subsection{Boundary conditions}

The rain rate and evaporation rate are imposed as a flux for the upper boundary condition. For the snow-atmosphere interface, rain and evaporation rates replace $\Phi_{i, \text { top }}^{t+1, k+1}$ and $\Phi_{i, \text { top }}^{t}$. Both rain and evaporation fluxes are provided from the meteorological forcing.

The lower boundary is the soil snow interface. There are two options for the bottom boundary: one uses soil properties from the ISBA soil routine, the other is a free-flowing bottom boundary.

\subsubsection{Bottom boundary with soil properties}

Properties from the upper-most soil layer are imported from the Surfex/ISBA soil routine, which also uses the Richards equation for unsaturated water flow. Interfacial conductivity between the soil and bottom snow layer $K_{\text {bot }}$ is calculated with Eq. (12) using the top soil layer hydraulic conductivity and thickness. The top soil layer's pressure head and thickness are used in Eq. (11) to calculate flux to soil $\Phi_{i, \text { bot }}^{t+1}$. Both the soil properties and flux at snow pack surface remain constant over the routine inner time steps and are updated on the time step ( $\left.T_{\text {Crocus }}\right)$. 


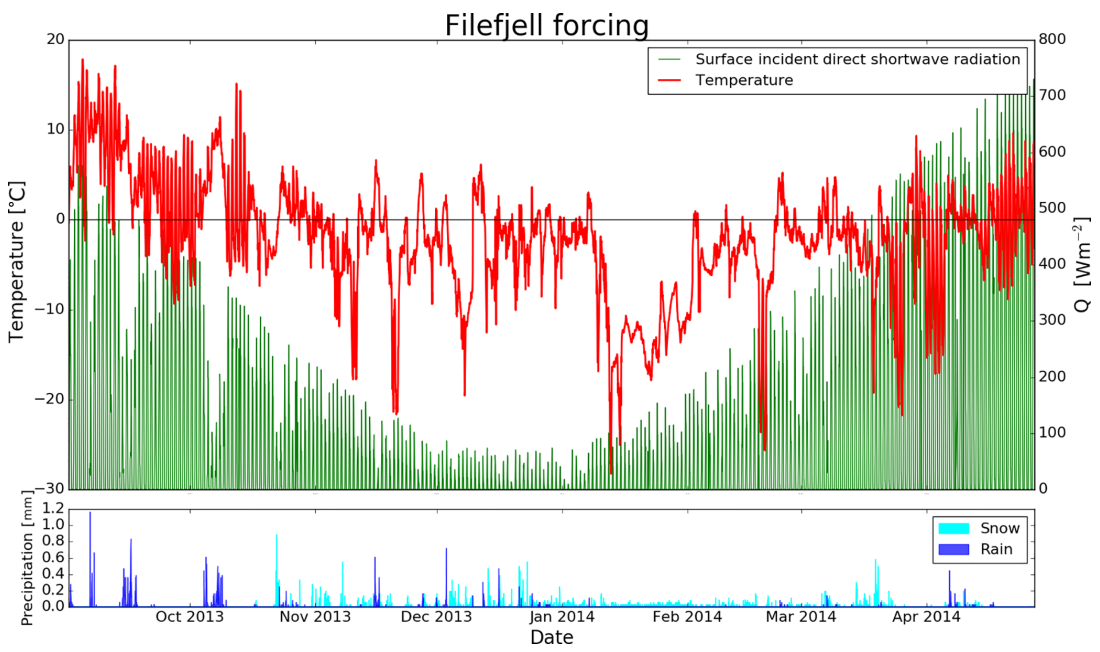

Figure 4. Forcing data from an automatic weather station located at Filefjell, Norway, for the period 1 September 2013 to 31 May 2014.

\subsubsection{Free-flow bottom boundary}

A free-flowing bottom boundary has been added where the pressure gradient of the last two snow layers is applied at the bottom boundary. The hydraulic conductivity of the last snow layers is used at the snow-soil interface. Water cannot move from the soil to the snowpack. If the pressure gradient of the bottom two snow layers is upward, the pressure at the snowsoil interface is set to $0 \mathrm{~m}$. All plots shown in this paper use the free-flowing boundary.

\section{Forcing data and experiments}

The Richards routine was tested on two data sets: one is from Filefjell, Norway $\left(61.178231^{\circ} \mathrm{N}, 8.112925^{\circ} \mathrm{E}\right)$, recorded at an automatic weather station by the Norwegian Water and Energy Directorate (NVE), and the other is a synthetic data set.

\subsection{Filefjell}

The Filefjell data set was recorded at hourly steps over the 2013-2014 winter at a flat field at $956 \mathrm{~m}$ a.s.1. Filefjell is located about $200 \mathrm{~km}$ northwest of Oslo. Despite being $30 \mathrm{~km}$ inland from the end of a fjord, Filefjell is considered to have a continental snow climate, which has an average precipitation of $603 \mathrm{~mm} \mathrm{yr}^{-1}$ and large annual temperature variation, shown in Fig. 4. Continental snow climates are characterized by thin snow covers, cold temperatures and few rain-on-snow events during the winter months (McClung and Schaerer, 2006). Air temperatures become as cold as $-28.3^{\circ} \mathrm{C}$, and after January there is a long cold spell during which temperatures stay well below zero for about a month. The surface incident shortwave radiation is low during winter, when maximum daily values are below $300 \mathrm{~W} \mathrm{~m}^{-2}$ from 18 October 2013 to 19 February 2014, due to the high latitude. The first large rain-on-snow event occurs on 7 March 2013, with a second event on 6 and 7 April 2013. Early winter rain-onsnow events occurred before January, which is not typical for continental climates. Unfortunately, no manual snow pit measurements at the field site have been conducted during the winter of 2013-2014.

\subsection{Synthetic}

Figure 5 shows the 90 -day synthetic data set. The peak shortwave radiation values for this data set are low and increase linearly from 100 to $200 \mathrm{~W} \mathrm{~m}^{-2}$. Temperature has a linear increase from 265 to $276 \mathrm{~K}$. The temperature and radiation patterns set in the synthetic data set were chosen to induce a modest melt rate early in the simulation that is ramped up to a heavy melt rate at the end of the simulation. The synthetic data set is designed to test the new routines for a large range of water supply rates. This data set has two large snow events: the first one starts on day 3 and deposits $2.6 \mathrm{~m}$ over 5 days, and the second event occurs on day 60 after the first snow event had a chance to settle down to $1.1 \mathrm{~m}$ and the diurnal radiation cycle had formed a melt freeze crust at the surface. The second snowfall buried the old surface crust under $1.8 \mathrm{~m}$ of snow (for Richards routing, 1.9 for bucket routine). The second snowfall was deposited with density variations, an effect of the radiation cycle. The synthetic data set allows for a simple comparison between the Richards routine and bucket routine without complicated snowpack structures, over a wide variety of melt intensities.

\subsection{SURFEX configuration of the model runs}

The snow metamorphism routine SNOWCROMETAMO (Fig. 1) uses the C13 routine from Carmagnola et al. (2014) as the default metamorphism routine, although other options exist. The $\mathrm{C} 13$ routine uses optical diameter and spheric- 


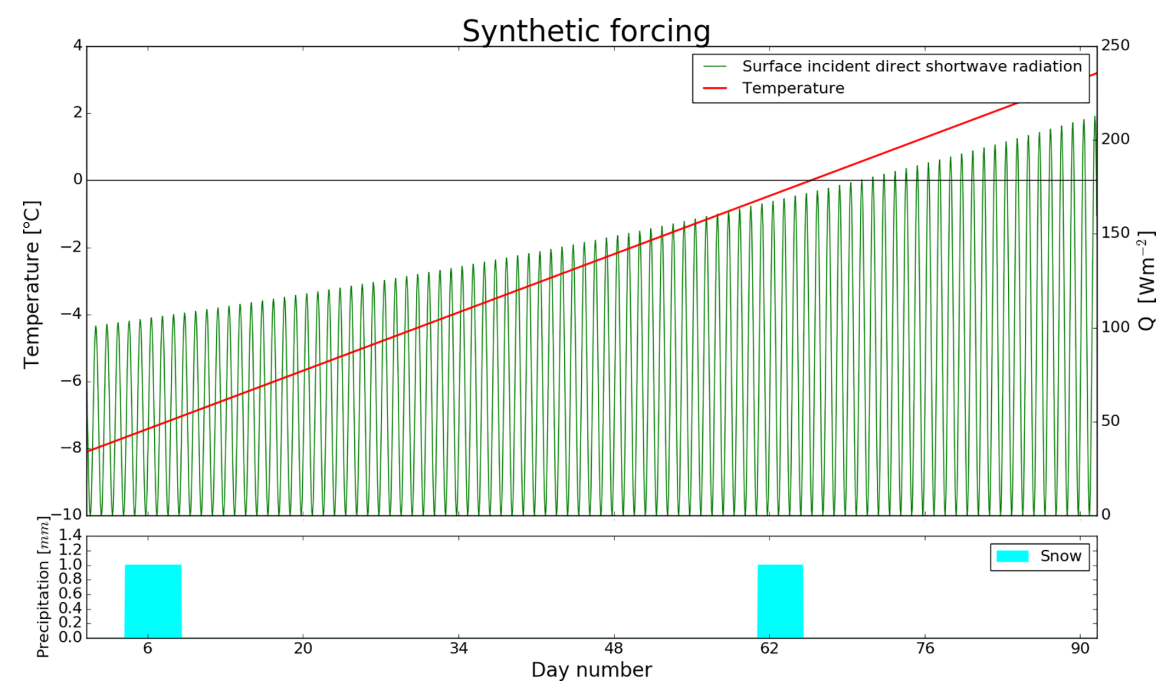

Figure 5. Simulated forcing data. Temperature (red) and net radiation (green) both linearly increase, creating low melt early in the simulation and high melt at the end of the data set.

ity to describe the microstructure of snow. The free-flowing boundary was used for the bottom boundary condition in the Richards routine. The default time step ( $\left.T_{\text {Crocus }}\right)$ was used unless otherwise specified. Every $900 \mathrm{~s}$ the prognostic and diagnostic variables were saved despite duration of $T_{\text {Crocsu }}$.

\section{Results}

\subsection{Filefjell Simulation}

Simulation results for the Filefjell data set are presented in Fig. 6, with the top (Fig. 6a and b) showing the amount of liquid water and snow layer density from the simulation run with the bucket routine and the bottom (Fig. 6c and d) with the Richards routine. The snowpack thickness reaches just over $1 \mathrm{~m}(1.1 \mathrm{~m}$ for the Richards routine and $1.2 \mathrm{~m}$ for the bucket routine) at its maximum in March before a fast melt out. The difference in snow thickness between the two routines is due to the wet-snow compaction that relies on the LWC. The majority of the snowpack wetting occurs during the April melt. The wetting front reaches the bottom of the snowpack at approximately the same time independent of which routine was used (Fig. 6a and c). The three rain and melt events that occur early in the season (23-24 October, 15 and 26 November) pass water to the soil layers for both percolation routines. The two melt and rain events that occur after the cold period in January (7 March and 6-7 April) cause the surface layers to get wet, while deeper layers remain below freezing. These two events are more pronounced and reach deeper snow layers in the simulation using the Richards routine. The event on 7 March formed a layer with density $\sim 300 \mathrm{~kg} \mathrm{~m}^{-3}$ (at 0.7 to $0.9 \mathrm{~m}$ ) when run with the Richards routine, which is missing from simulations using the bucket routine (see Fig. 6b and d).
The density evolution according to the bucket routine (Fig. 6b) shows the formation of a dense crust at the bottom of the snowpack of about $375 \mathrm{~kg} \mathrm{~m}^{-3}$, where the Richards routine (Fig. 6d) creates a much thicker and denser layer of $>600 \mathrm{~kg} \mathrm{~m}^{-3}$. The Richards routine makes a slightly denser preisothermal snowpack and a much denser snowpack during periods of enhanced water transport. The bucket routine allows easy transmission through crust layers because highdensity layers yield low pore volumes resulting in a "small bucket size". The bucket routine does not represent crust layers well because they develop to be too thick and not dense enough.

\subsection{Synthetic data set's simulation}

The synthetic data set results are presented in Fig. 7, illustrating simulations utilizing the bucket routine and Fig. 8, showing simulation using the Richards routine. Figures $7 \mathrm{c}$ and $8 \mathrm{c}$ are zoomed in on the second snow event. The percentage of pore space that is filled by water (saturation) is the measure used to calculate the "bucket size" which makes it an intuitive way to view water content for the bucket routine. The results of the bucket simulation show a uniform wetting front that features a stepped pattern (Fig. 7a). The stepped pattern arises from the diurnal cycle of water input at the surface. With the Richards routine, water percolates during the high and low phase of the diurnal radiation cycle, which results in a faster water front progression and a lack of the stepped pattern (Fig. 8a). There is also a big variance in the percentage of pore space filled with water throughout the simulation. Effects of the diurnal cycle are visible in the Richards routine's results, in the form of percolation fronts that move down the snow layers. 

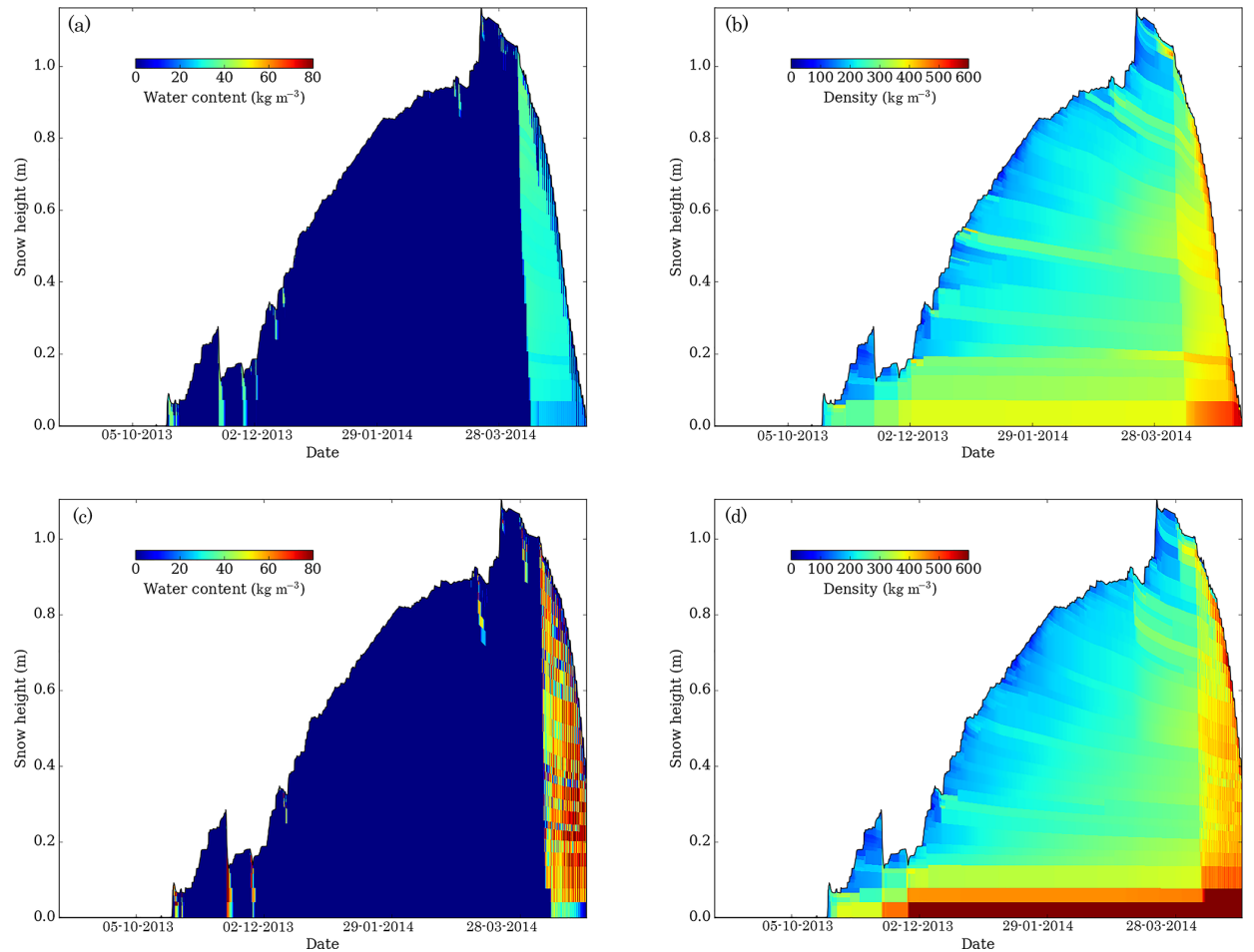

Figure 6. Crocus output from Filefjell, Norway, in which the top plots use the bucket routine and the bottom plots use the Richards routine. Panels $(\mathbf{a}, \mathbf{c})$ show distribution of liquid water, and $(\mathbf{b}, \mathbf{d})$ show the density distribution. $T_{\text {crocus }}=900 \mathrm{~s}(15 \mathrm{~min})$ was the time step duration.
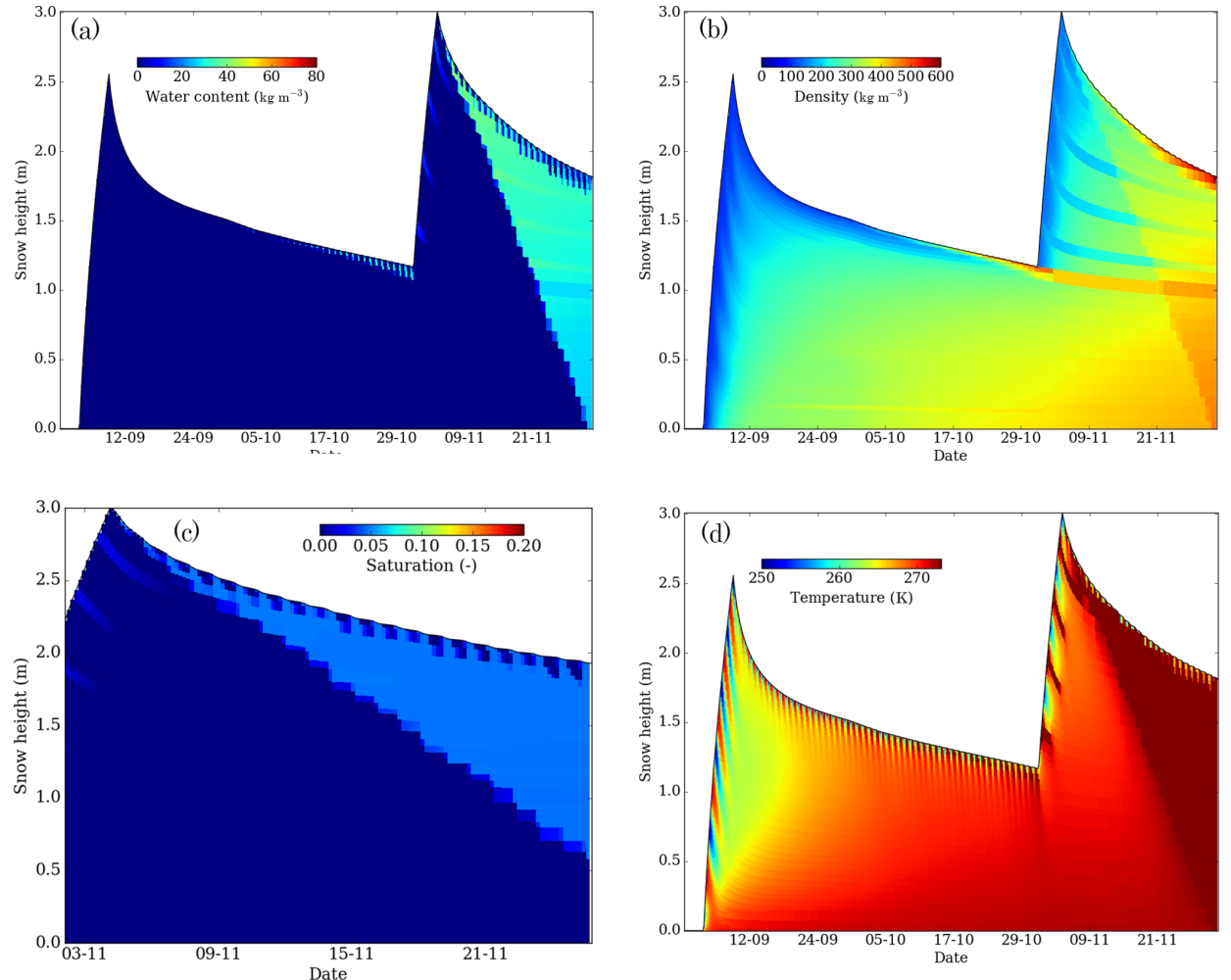

Figure 7. Crocus output for simulated forcing using the bucket routine with $T_{\text {Crocus }}=900 \mathrm{~s}$ ( $\left.15 \mathrm{~min}\right)$, plotted every $3 \mathrm{~h}$, except for (c), which is plotted every $15 \mathrm{~min}$. (a) Liquid water amount, (b) snow layer density, (c) percentage of pore volume filled with water zoomed in on the second snow event and (d) temperature development of the snowpack. 

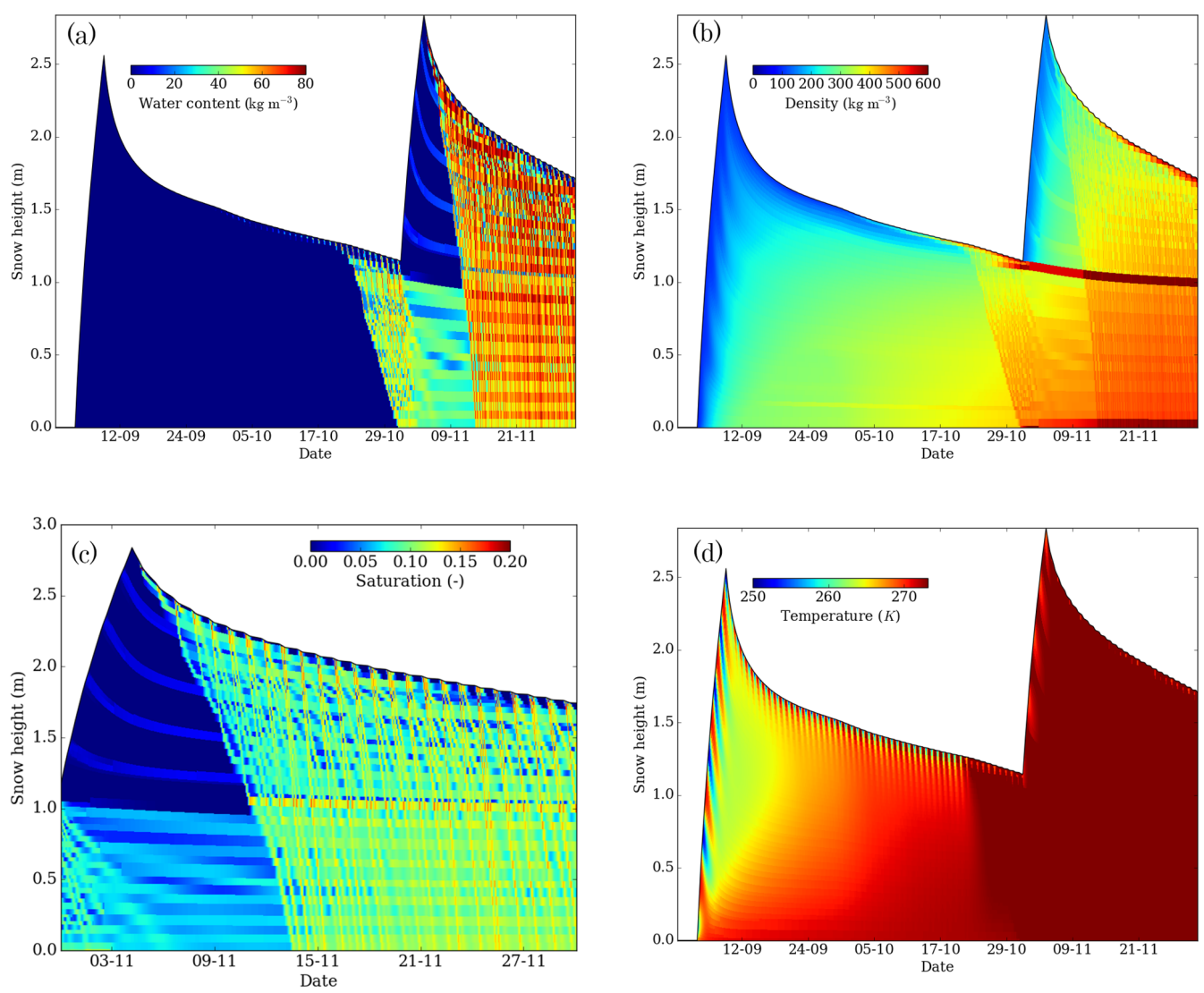

Figure 8. Crocus output for simulated forcing using the Richards routine with $T_{\text {Crocus }}=900 \mathrm{~s}$ ( $15 \mathrm{~min}$ ). The bottom boundary is set to free flow, with $\theta_{\min }=10^{-5}$. (a) Liquid water amount, (b) snow layer density, (c) percentage of pore volume filled with water zoomed in on the second snow event and (d) temperature development of the snowpack.

A pattern emerges after meltwater from after the second snow event reaches the bottom snow layer Fig. 8a where yellow and red stripes appear (also seen in Figs. $6 \mathrm{c}$ and 8c, albeit less pronounced). Every second snow layer remains very wet with $10-12 \%$ pore volume corresponding to a water content of $60-80 \mathrm{~kg} \mathrm{~m}^{-3}$. Figure $8 \mathrm{c}$ shows interesting behavior of many newly wet-snow layers quickly draining to less than $5 \%$ saturation after the water front has percolated to deeper layers.

The bucket routine run with the synthetic forcing (Fig. 7b), produces a thick crust layer that does not exceed a density of about $400 \mathrm{~kg} \mathrm{~m}^{-3}$. There is no delay in the water front's movement as it passes the melt freeze crust in Fig. 7b. The Richards routine produces a melt freeze crust that is thicker and more dense (about $500 \mathrm{~kg} \mathrm{~m}^{-2}$ ) than the bucket routine.

\subsection{Sensitivity of prewetting and time step}

The temperature development of the snowpack for both the Richards and bucket routines lead the wetting front. However, changing the length of $T_{\text {Crocus }}$ (Fig. 9) will change the timing of the warming and water front. When $T_{\text {Crocus }}$ is re- duced the warming and wetting front is able to percolate much faster.

If $\theta_{\min }$ is larger than $10^{-5}$ the temperature of the snowpack would become isothermal long before the wetting front. If $\theta_{\min }$ is kept below $10^{-5}$ the temperature and water distribution are not changed significantly. Appendix A discusses a sensitivity test on the prewetting amount and how the default $\theta_{\min }$ was set.

\subsection{Feedback from compaction and metamorphism routines}

There is substantial feedback between the snow grain metamorphism routine (SNOWCROMETAMO), the snow compaction routine (SNOWCROCOMPACTN) and the parameterizations. Parameterizations for the water retention curve and the hydraulic conductivity function depend on the grain size and the density of snow layers, which in turn are altered by metamorphism and compaction. Crystal metamorphism is accelerated when the snow is wet and the viscosity of the snow layer further enhances the compaction rate. The wet-snow compaction rate and the wet-snow metamorphism were developed to work with the bucket model, 

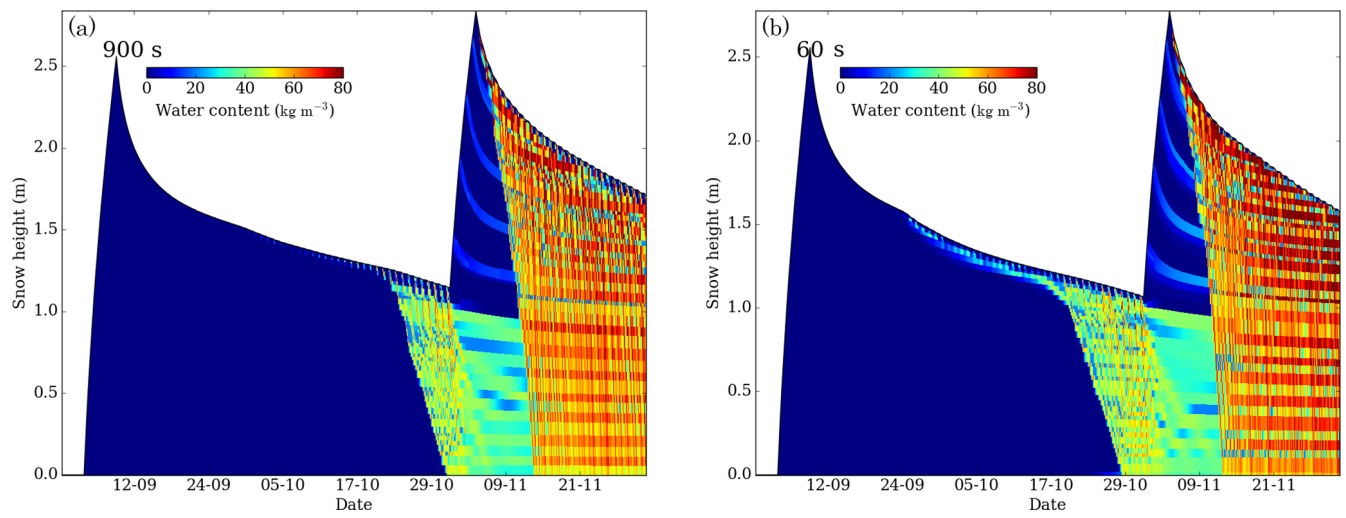

Figure 9. Crocus output for simulated forcing showing different time steps: (a) $T_{\text {Crocus }}=900 \mathrm{~s}$ ( $15 \mathrm{~min}$ ), (b) $T_{\text {Crocus }}=60 \mathrm{~s}$ both plots use the free-flowing bottom boundary with prewetting set to $\theta_{\min }=10^{-5}$. The $60 \mathrm{~s}$ simulation has water at the bottom of the snowpack 4 days before the $900 \mathrm{~s}$ simulation.
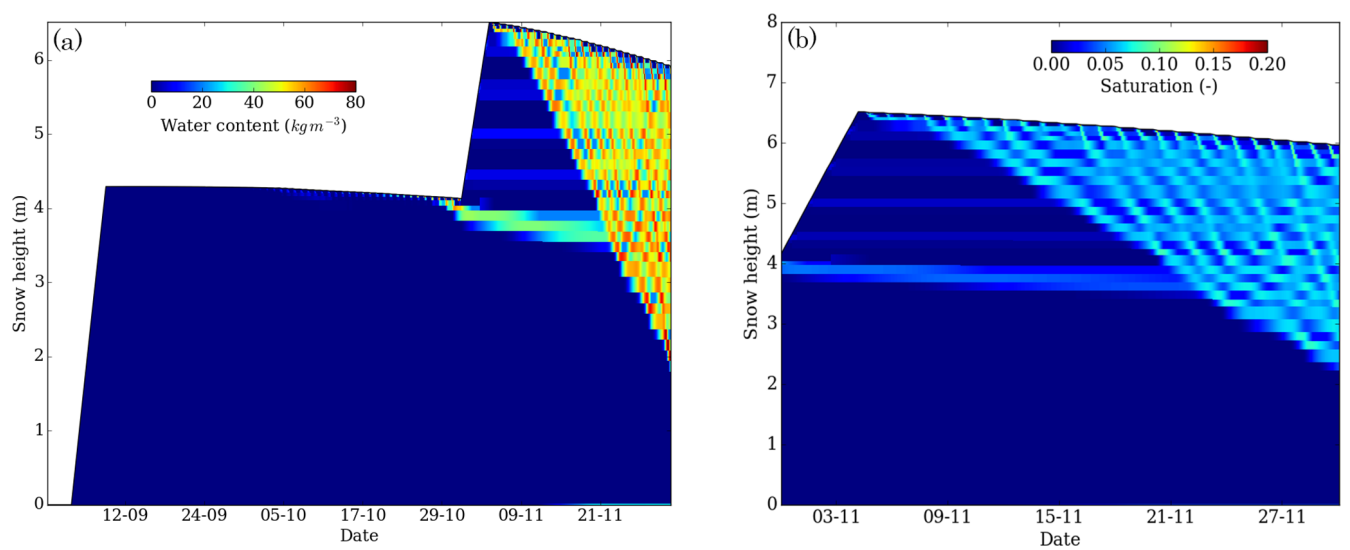

Figure 10. Crocus output for simulated forcing with SNOWCROMETAMO (snow metamorphism routine) and SNOWCROCOMPACT (snow compaction routine) turned off. The time step $t$ was restricted to maximum of $30 \mathrm{~s}$ for numerical stability. Panel (a) shows water content $\left(\mathrm{kg} \mathrm{m}^{-3}\right)$ and (b) is the saturation (unitless); these plots show that without feedback the Richards routine percolates water down the snowpack with maximum $\mathrm{LWC}<10 \%$.

which keeps snow layers moderately wet and firmly in the pendular regime. The bucket routine is much less dynamic in regard to fluctuations of water content. The alternating horizontal stripes (yellow, red pattern in Fig. 8a) in water content apparently are influenced by snow properties, as demonstrated in a numerical experiment in which snow metamorphism (SNOWCROMETAMO) and compaction (SNOWCROCOMPACTN) routines have been disabled, resulting in the disappearance of these stripes (Fig. 10). However, Fig. 10 should be interpreted with care because turning off SNOWCROMETAMO and/or SNOWCROCOMPACTN results in unphysical snowpack conditions, beyond the domain for which the parameterizations have been originally designed for.

\section{Discussion}

Comparing Figs. 7a and 8a shows that the Richards routine creates an isothermal snowpack and water percolation to deep layers earlier in the simulation than the bucket routine. However, the propagation of the warming and water fronts depends on many variables. The following sections discuss some of the parameters that we found to have influence over the timing and amount of water flow and some of the limitations and assumptions used in the routine.

There is a substantial CPU time increase in running the Richards routine compared to the bucket routine. The synthetic data simulation, run at $15 \mathrm{~min}$ resolution, was $9 \%$ slower when using the Richards routine. However, to produce plots such as Figs. 7 and 8 requires the Richards routine to use a $15 \mathrm{~min}$ time step, whereas the bucket routine can reproduce Fig. 7 with a $3 \mathrm{~h}$ time step; the load of more frequent 
output saving may further contribute to increase the difference in computational cost.

\subsection{Liquid water content magnitude}

The bucket routine has a LWC upper limit of $5 \%$ pore space. There are two wetness states that are frequented in the bucket routine, the dry state and wet state at holding capacity. A snow layer spends little time over the course of a snow season in the transition between dry and at holding capacity, which can be seen in Figs. $6 \mathrm{~b}$ and 7c. Routines such as the compaction and grain metamorphism were developed using the bucket routine and rely on a nearly binary water content configuration.

Using the Richards routine, we obtain much higher LWCs, which constantly vary between time steps (Figs. 6c and 8a). The Richards routine is capable of wetting snow layers to the transition between pendular and funicular regimes, as defined by Denoth (1980), in which $18 \%$ of the simulated data sets' snow layers that entered the percolation routine had $>10 \%$ of their pores filled with water. This study did not investigate how other routines in Crocus (e.g., the compaction routine) that are affected by the LWC are affected by high LWCs in snow layers. However, it is expected that wet-snow compaction and wet grain metamorphism are nonlinear functions with feedback on LWC in the transition between pendular and funicular, since the physical distribution of water is held differently in the snow's pores with respect to snow crystal surfaces (Denoth, 1982).

\subsection{Bottom boundary}

The bottom boundary is an area of concern because it feeds the soil water percolation routine with meltwater, and differences in pore structure over the snow-soil interface will often create a textural barrier, which can lead to pooling or accelerated flow. The advantage of running the Crocus model coupled with SURFEX and ISBA is that the boundaries of the Crocus model (atmosphere and soil) are better represented and dynamic. The free-flowing boundary does not take advantage of the coupling between Crocus and ISBA, but shows better results in the current organization of SURFEX, ISBA and Crocus. We recognize the bottom boundary as a part of the routine that needs more development, so that the Richards routine can take full advantage of SURFEX and ISBA.

\subsubsection{Bottom boundary with soil properties}

The performance of the bottom boundary when soil conditions are used is not satisfactory. The flux to the soil remains lower than when the free-flowing boundary is used. This results (not shown) in higher saturations of all snow layers after the bottom snow layer becomes wet. The higher LWCs increase the feedback from other crocus routines, thus enhancing the "yellow/red striped pattern" (seen in Fig. 8a).
When using the upper soil layer as lower boundary for the snowpack, the hydraulic conductivity of the bottom soil layer and the suction of the soil layer are imported to Crocus from the soil routine. These values are held fixed for the time step $T_{\text {Crocus }}$. The hydraulic conductivity of the bottom interface is the arithmetic mean (harmonic mean can be used) of the bottom snow layer and the top soil layer's thickness and hydraulic conductivity. Snow layers are able to move water between them on the internal time step $(t)$, which can be as small as a fraction of a second. Snow layer suction and conductivity are altered on the internal time step $(t)$. However, the soil suction and conductivity remains constant until $\Sigma t=T_{\text {Crocus }}$ which means the snow-soil interface has less-dynamic conductivity and suction because half the values making up the $K_{\text {snow--soil }}$ are constant on $T_{\text {crocus }}$. One way to force the bottom interface to be more dynamic is to reduce $T_{\text {Crocus }}$ (Sect. 5.3). A second way is to increase the top soil layers' thickness, in which case the snow layer will dominate in the weighted average used for conductivity at the snow-soil interface. However, increasing the size of the soil reduces the reliability of the snow-soil thermodynamics routine, but that is beyond the scope of this study.

Ideally, the snowpack and soil column would be solved as one continuous column (Wever et al., 2014). However, the snowpack is semiimplicitly coupled to the soil percolation routine on $T_{\text {Crocus }}$. Unfortunately, with the ISBA model the soil and snow routines are not coupled on the variable time step $t$. To solve the soil and snow as one continuous column of unsaturated porous media would take major reorganizing of the SURFEX model and was not feasible during this study, but should be considered in the future.

\subsubsection{Free-flow bottom boundary}

The free-flowing bottom boundary does not require adaptation of soil layer thicknesses. The free-flowing bottom boundary is identical to how the bucket routine interacts with the soil layers. The drawback of the free-flowing boundary is that there is no feedback to Crocus from the soil routine, yet the soil routine is affected by the snow through the water flux. The free-flowing boundary can be applied for the many applications that do not need the snow interacting with soil. However, for some applications water flux from the soil to the snow is critical and the free-flowing boundary cannot reproduce this interaction. A big motivation for implementing the Richards routine in Crocus was to enhance the simulated snow-soil interactions. The free-flowing boundary was implemented as a workaround for a poorly functioning bottom boundary condition. Further development is needed on coupling the soil to the snow, which might require major changes to SURFEX's structure. 


\subsection{Coupling}

$T_{\text {Crocus }}$ dictates the degree of coupling between SURFEX routines, including the coupling between the ISBA and Crocus and between routines in Crocus. The water percolation process is coupled to the soil percolation process and the energy balance of the snowpack; in Crocus these routines are run sequentially and are coupled via $T_{\text {Crocus. }}$. The energy balance is made up of many processes that are expressed through many of the routines in Crocus (see Fig. 1). The temperature of the snow layers is altered after the percolation routines (for both Richards and bucket) due to latent heat release, if refreezing occurs. Although a sensitivity study on the link between temperature of snow layers and percolation would be relevant, such a study was not possible because of other feedbacks in the model.

The histograms in Figs. 2 and 3 show the distribution of snow layer saturation upon entry to the Richards routine. The water content is often very low, with $49.5 \%$ of the snow layers under $5 \%$ LWC for the simulated data set. At low saturations, the hydraulic conductivity function and the retention curve are very sensitive to changes in density, grain size and saturation. It is important to note that a $1 \%$ change in saturation when very dry can affect both the hydraulic conductivity and the water retention curves by orders of magnitude. Figure 9 shows the simulated forcing when run with $T_{\text {Crocus }}=900 \mathrm{~s}$ and $T_{\text {Crocus }}=60 \mathrm{~s}$. Water moves through the snowpack earlier when $T_{\text {Crocus }}=60 \mathrm{~s}$ because feedback between the percolation routine and routines that alter layer density and layer grain size are more effective and faster acting.

\subsection{Feedback from compaction and metamorphism routines}

There are two major differences between the Richards routine and the bucket model concerning the behavior of the water content within a snow layer. The bucket routine keeps water saturation at moderate levels, with very little fluctuation in saturation once the holding capacity is reached. In contrast, saturation of up to $90 \%$ of the pore space can be reached with the Richards routine (however, our saturations never reached $>20 \%$ with the simulated forcing), with constant small $(<1 \%)$ fluctuations in the saturation over the duration of the simulation. The cause of the striped pattern (in Fig. 8a) has been identified as stemming from an incomplete description of wet-snow metamorphism and compaction in the routines SNOWCROMETAMO and SNOWCROCOMPACTN (Fig. 1) which have been developed for use with the bucket routine. There is significant feedback between the Richards routine and the metamorphism and compaction routines in Crocus as the parameterizations used are heavily reliant on snow grain size and snow density. Figure 10 shows that the Richards routine is numerically stable, when run without feedback from the metamorphism and compaction routines, and does not produce the striped pattern.

Examining how an increase in grain size (or density) will affect the water retention curve and hydraulic conductivity with Figs. 2 and 3 highlights the complexity of the feedback system. Comparing the water retention curve for small rounds $\left(400 \mathrm{~kg} \mathrm{~m}^{-3}, 0.5 \mathrm{~mm}\right.$ diameter) with that of melt forms of identical density $\left(400 \mathrm{~kg} \mathrm{~m}^{-3}, 1 \mathrm{~mm}\right.$ diameter, Fig. 2) shows that the response of the water retention curve to an increase in snow grain size depends on the saturation of the snow layer. For instance, at low levels of saturation $(<0.2)$, a smaller grain size is associated with lower hydraulic head, but this is reversed at higher saturation levels at which smaller grains will induce a higher head. A similar grain size dependency is also observed for the hydraulic conductivity (Fig. 3). This means that as grains grow, the suction or hydraulic conductivity may increase or decrease depending on the saturation. Similar behavior holds for changing the density at a fixed grain size. This indicates that snow metamorphism can induce alternating gradients in hydraulic snow properties, eventually leading to the observed "striped pattern". This behavior appears nonplausible but the validity of the water retention curve and hydraulic conductivity parameterizations for the wet-snow regime needs to be established in future work before this issue can be resolved.

\subsection{Conductivity through crusts}

The Richards routine is able to produce crust layers from meltwater that the bucket routine cannot reproduce, like the melt freeze crust in Fig. 8b. However, the thickness and density of crust layers depend on where the percolation routine moves water, since refrozen liquid water is often the cause of crusts at the surface and inside the snowpack. The water retention curve and hydraulic conductivity functions are not designed for use on crust layers. Furthermore, Crocus' snow metamorphism routine (SNOWCROMETAMO, Fig. 1) does not work well for crust layers, because dense crusts do not have individual grains, but rather a solid ice layer with bubbles. There is a choice of routines in SNOWCROMETAMO, the $\mathrm{B} 92$ and the $\mathrm{C} 13$ routines. The $\mathrm{B} 92$ routine uses sphericity and dendricity. The $\mathrm{C} 13$ routine uses optical diameter, which is used as an approximation for visual grain size in the Richards routine. The assumption that optical diameter is a sound approximation for visual grain size is questionable, especially for crust layers. Nevertheless the metamorphism routine calculates a grain size for all layers including crusts (see Sect. 6.6). Figure $8 \mathrm{~b}$ shows that the crust layer was able to develop into a thinner and denser crust compared with the bucket routine Fig. $7 \mathrm{~b}$. Since there is no literature available on water retention and hydraulic conductivity of crust layers, crusts are treated like normal snow layers in both percolation routines.

The Richards equation is solved in one dimension normal to the snow surface. However, dye tracer experiments 
have shown that water transport though snow is a threedimensional process (Williams et al., 2010). When the wetting front reaches a barrier such as a crust or capillary differences, the underlying snow layer will probably develop flow channels where a one-dimensional model does not suffice. Averaging the hydraulic conductivity between a layer's barrier suction with the flow channel suction is one way to express a three-dimensional process in one dimension. Hydraulic conductivity has been determined (via permittivity) by Calonne et al. (2012) on small snow samples, and therefore it is likely that the measurements do not represent conductivity on a higher spatial scale because processes that affect the density distribution, grain metamorphism and pore space differ on scales of a meter to several meters (Birkeland et al., 1995).

\subsection{Grain metamorphism routine}

The hydraulic conductivity function derived from Calonne et al. (2012) utilizes the optical grain diameter and snow density. The hydraulic conductivity function pairs well with the C13 routine, because they both use optical grain diameter. However, the water retention curve (Yamaguchi et al., 2012) was based on visual grain size measurements and the use of optical grain diameter may hinder the performance of the water retention curve.

The pore shape and structure is important for the retention curve and the hydraulic conductivity. Small pores inside the snow layer create suction via capillary rise, and water travels through the voids in the snowpack. Both parameterizations could benefit from a better description of the pores' structure. Density and grain size is not enough to describe the pore structure of a snow sample. We use optical diameter for parametrization, but in nature optical properties do not influence the hydrological processes of snow. For the retention curve and the conductivity functions to be used at low saturations, pore shape and structure should be considered. Introducing a routine in Crocus that calculates pore shape could be beneficial for not only the water percolation routine but also the thermal conductivity (Riche and Schneebeli, 2013; Sturm et al., 1997). This would also require new parameterizations including a pore structure variable with the grain size and density.

\subsection{Water retention curve}

The Yamaguchi et al. (2012) water retention curve has been applied to melt-form crystal types and reported poor performance with rounded grains. It is expected that the retention curve does not represent precipitation particles, decomposing and fragmented precipitation particles, faceted crystals and depth hoar well. However, when water is present in a snow layer, snow grain metamorphism will transform all snow crystals into melt forms (Colbeck, 1976; Shimizu, 1970). This negative feedback on snow grain type could mean the melt forms are the only crystals that need to be described by a water retention curve, but this claim needs validation.

The residual water content is one of four parameters needed to define the water retention curve. The residual water content represents how dry a layer can get with maximum suction applied. A constant $\theta_{\mathrm{r}}$ was used for different grain types, sizes and densities but results from Adachi et al. (2012) and Leroux and Pomeroy (2017) suggest that $\theta_{\mathrm{r}}$ varies with grain size.

Hysteresis in the water retention curve stems from oddly shaped pores, which mean that pores can hold different amounts of water at the same hydraulic head depending on the initial LWC. In most cases, snow will go from a dry state (pore space filled completely with air) and become wet. The Yamaguchi parameters for the van Genuchten model are derived from a drainage experiment, in which the pore space was completely filled with water and allowed to drain. Adachi et al. (2012) showed that the shape of the water retention curve is affected more in fine-textured grains than coarse grains.

Parametrization of the water retention curve based on a wider range of snow grain types and sizes are needed to represent natural snow pack conditions. For fine-textured snow, parameter sets derived from wetting experiments would be beneficial, as the snow usually starts from a dry state.

\section{Conclusion}

A water percolation routine that solves the Richards equation was added to the Crocus model as a physically based alternative to the empirical bucket routine. However, the performance of the Richards routine is not sufficient for simulations of the snowpack, because further work is needed on other parts of the Crocus model that feedback on the parameter sets used by the Richards routine.

The bucket model keeps snow layers in the pendular wetness regime. The Richards routine reaches LWCs much higher than the bucket routine, with water filling $>17 \%$ pore volume for many snow layers, which lies in the funicular regime for all snow types. However, $18 \%$ of snow layers entered the Richards routine with $<10 \%$ of the pore space filled with water (bucket routine has max $5 \%$ ). With small changes in LWC at low saturation, the suction and hydraulic conductivity can change by orders of magnitude.

The wet-snow metamorphism and wet-snow compaction routines were implemented when the bucket model was the only option for water transport. There is a physical difference in the distribution of water inside the pores between pendular and funicular regimes. This difference is not accounted for in the snow compaction rate or wet-snow metamorphism rates, which leaves feedbacks to the new routine open to question.

The parameterizations used are heavily reliant on the snow grain size and the density of snow layers. New parameterizations for the hydraulic conductivity and the water reten- 
tion curve that do not contain grain size are needed for dense crust layers. The Richards routine in the current state treats crusts as a normal snow layer in which grain size calculations are erroneous. The parameterization for the water retention curve was based on a small domain of densities, grain sizes and snow types. In the future, the domain for this parameter set should be expanded for applicability in snow grains other than melt forms. New parameter sets should be based on wetting experiments for small grain sizes as hysteresis affects the Van Genuchten parameters $\left(\theta_{\mathrm{r}}, \alpha, n\right)$.

The snow-soil interface does not perform well during periods in which large amounts of meltwater should pass from the snowpack to the soil. Soil parameters (suction and hydraulic conductivity) are updated on a 15 min time step, which is not fast enough during periods of high water flux. At the current state of the Crocus model, major structural changes are needed in order to couple the soil and snow on the variable time step used by the Richards routine. A freeflowing bottom boundary shows better results during high flux periods but does not take advantage of the ability to run Crocus in SURFEX coupled with ISBA.

Because of the number of areas of concern in the validity of the Richards routine, we did not attempt a validation experiment. In order to further develop the Richards routine, improvements and updates are needed in other Crocus routines (mostly melt, compaction and grain metamorphism) and/or the parameter sets used by the Richards routine, which is beyond the scope of this study.
Code and data availability. For directions and help with downloading, compiling and running the code you will need to register as a user at https://opensource.umr-cnrm.fr/. The SURFEX/CrocusV7 with the Richards routine can be downloaded via Git by following instructions at https://opensource.umr-cnrm.fr/ projects/snowtools/wiki/Install_SURFEX and downloading the branch "damboise_dev" with the "damboise_et_al.2017" tag. Directions for running SURFEX (with Crocus) can be found here: https://opensource.umrcnrm.fr/projects/snowtools/wiki/ Basic_functioning_of_SURFEX_without_the_s2m_tool_from_ snowtools. The Wiki can be a useful resource for troubleshooting https://opensource.umrcnrm.fr/projects/snowtools/wiki/Wiki.

The Filefjell and simulated data set with the namelist needed for running the simulations are provided at www. norstore.no. - https://doi.org/10.11582/2017.00010 (NVE, 2017a), https://doi.org/10.11582/2017.00009 (NVE, 2017b). 


\section{Appendix A: Picard iteration and convergence}

A Picard iteration is used to deal with the nonlinear nature of the system of equations. There are three convergence tests that need to be satisfied to calculate the next internal time step $(t)$. The three convergence criteria are on pressure head differences, volumetric water content differences and the mass balance (of individual snow layers) differences between two iterations and must be below $10^{-4} \mathrm{~m}$. Hence, there must be at least two iterations performed in order to test for convergence. If the current iterations' deviations of pressure, volumetric water content and mass balance are smaller than the error threshold that has been set, then the convergence criteria are met and the model proceeds to the next time step. The threshold of $10^{-4} \mathrm{~m}$ is a large amount of water considering it can be added at every time step $t$. However, the simulated data set has a maximum mass balance of $0.0011 \mathrm{~kg} \mathrm{~m}^{-1} \mathrm{~s}^{-1}$ over the full domain over $T_{\text {crocus }}(15 \mathrm{~min})$. The $15 \mathrm{~min}$ mass balance over the full domain is acceptable, when considering the synthetic data set was made to test extreme wetting and drying cycles, and snow layers often reach $\mathrm{LWC}>10 \%$ which is seldom the case in nature. Addressing the feedback issues described in Sects. 5.4 and 6.4 should reduce the number of layers at a high LWC and duration layers remain at high LWC.

A set of rules are used to regulate the variable time step based on the number of iterations needed for convergence, similar to Paniconi and Putti (1994). A maximum number of iterations has been set to 15 . If the calculations do not converge by the 15th iteration then the time step is reduced and calculations are preformed again, until the calculations converge within 15 time steps. The variable time step can range in time from about $400 \mathrm{~s}$ to fractions of a second within a lower limit of $1 \times 10^{-10} \mathrm{~s}$. Smaller time steps within the Richards routine result in the model taking too long to run or convergence not being achieved. If convergence is reached in 4-7 iterations the time step is kept constant. Converging in less than 4 or between 8 and 15 iterations results in a longer or shorter time step, respectively (Eq. A1).

$t^{i+1}= \begin{cases}t^{i} \cdot 1.5^{\mathrm{BS}}, & I<4 \\ t^{i}, & 4 \leq I<7 \\ t^{i} \cdot 0.5^{\mathrm{SS}}, & 7 \leq I<15 \\ \text { back step, } & 15<I\end{cases}$

Here, $I$ is the number of iterations and "back step" stops the calculation before convergence and reduces the $t^{i}$. BS and SS are initialized at 1 and is increased by 1 for the previous "bigger steps" or "smaller steps". BS and SS are reinitialized if the time step remains the same size $(4 \leq I<7)$.

\section{Appendix B: Alternative parameter sets}

The following sections describe alternative parameter sets for hydraulic conductivity (Sect. B1) and water retention curve
(Sect. B2, B3) that we implemented in the Richards routine, but is not presented in this paper.

\section{B1 Shimizu (1970)}

Shimizu developed a statistical model for $k_{\text {sat }}$ from the density and grain size of fine-grained compact snow, Eq. (B1). Shimizu suggests that other snow grain types and densities may give different coefficients to those found in Eq. (B1). For use in the Richards routine this parameter set would have to be applied to lower density snow than that used to create it.

Equation (B1) relates snow density and grain size to conductivity at saturation $\left(k_{\mathrm{sat}}\right)$.

$$
\begin{aligned}
k_{\text {sat }} & =0.077 \cdot\left(\frac{D}{2}\right)^{2} \cdot \exp \left(-0.078 \cdot \rho_{\text {snow }}\right) \\
\cdot & \left(\frac{G \cdot \rho_{\text {water }}}{\mu_{\text {water }}}\right)
\end{aligned}
$$

\section{B2 Yamaguchi et al. (2010)}

This parameter set was the prior work of the parameter set used in this study. Two major differences (when compared with Yamaguchi et al., 2012) for this parameter set are $\alpha$ and $n$, which are functions of grain diameter $(D)$ and not density. The density range used in the Yamaguchi et al. (2010) parameterization is small, $545-553 \mathrm{~kg} \mathrm{~m}^{-3}$. The parameterization for the $\theta_{\mathrm{r}}$ and $\theta_{\mathrm{s}}$ are the same as in Yamaguchi et al. (2012).

$$
\begin{aligned}
& \alpha=7.3 \cdot(D \cdot 1000)+1.90 \\
& n=15.68 \cdot \exp (D \cdot 1000) \cdot(-0.46)+1.00
\end{aligned}
$$

\section{B3 Daanen and Nieber (2009)}

Daanen and Nieber derived these relations based on measurements of liquid water content and water pressure from Marsh (1991)hey assume snow crystals to be between 1 and $0.1 \mathrm{~mm}$. However, descriptions of the measurements are not given in detail. The Daanen and Nieber study focuses on a framework of a coupled temperature and liquid water routine that does not focus on deriving the Van Genuchten fit parameters in a suitable way for different snow types, as all crystals are assumed to be spheres.

$$
\begin{aligned}
& \alpha=30 \cdot(D \cdot 1000)+12.00 \\
& n=0.8 \cdot(D \cdot 1000)+3.00 \\
& \theta_{\mathrm{r}}=0.05 \\
& \theta_{\mathrm{s}}=\text { Porosity }
\end{aligned}
$$




\section{Appendix C: Prewetting}

In order to apply the Richards equation in snow the Van Genuchten parameterization needs snow layers to have a small amount of liquid water. The amount of "prewetting", is set by $\theta_{\min }$. A sensitivity study was done on $\theta_{\min }$ because the parameter is not physical but necessary for numerical stability. The results showed that the temperature, density and liquid water content of the snow layers were not sensitive when $\theta_{\min } \leq 10^{-5}$. The temperature evolution of the snow pack is drastically different when $\theta_{\min }>10^{-5}$, although the timing of the percolation front and the distribution of water in the snowpack is not affected much. When too much water is used for prewetting, the snowpack becomes isothermal when the surface becomes wet (Fig. C1). Therefore the default value of $\theta_{\min }=10^{-5}$ was chosen. Figure $\mathrm{C} 1$ shows how the temperature evolution is affected by the magnitude of $\theta_{\min }$. If $\theta_{\min }$ is too large the snow pack becomes isothermal quickly after the top snow layer becomes wet for the first time. However if $\theta_{\min }$ is too low the simulation may not converge, or the simulation takes much longer to run because of the extreme pressure difference between wet and dry layers.
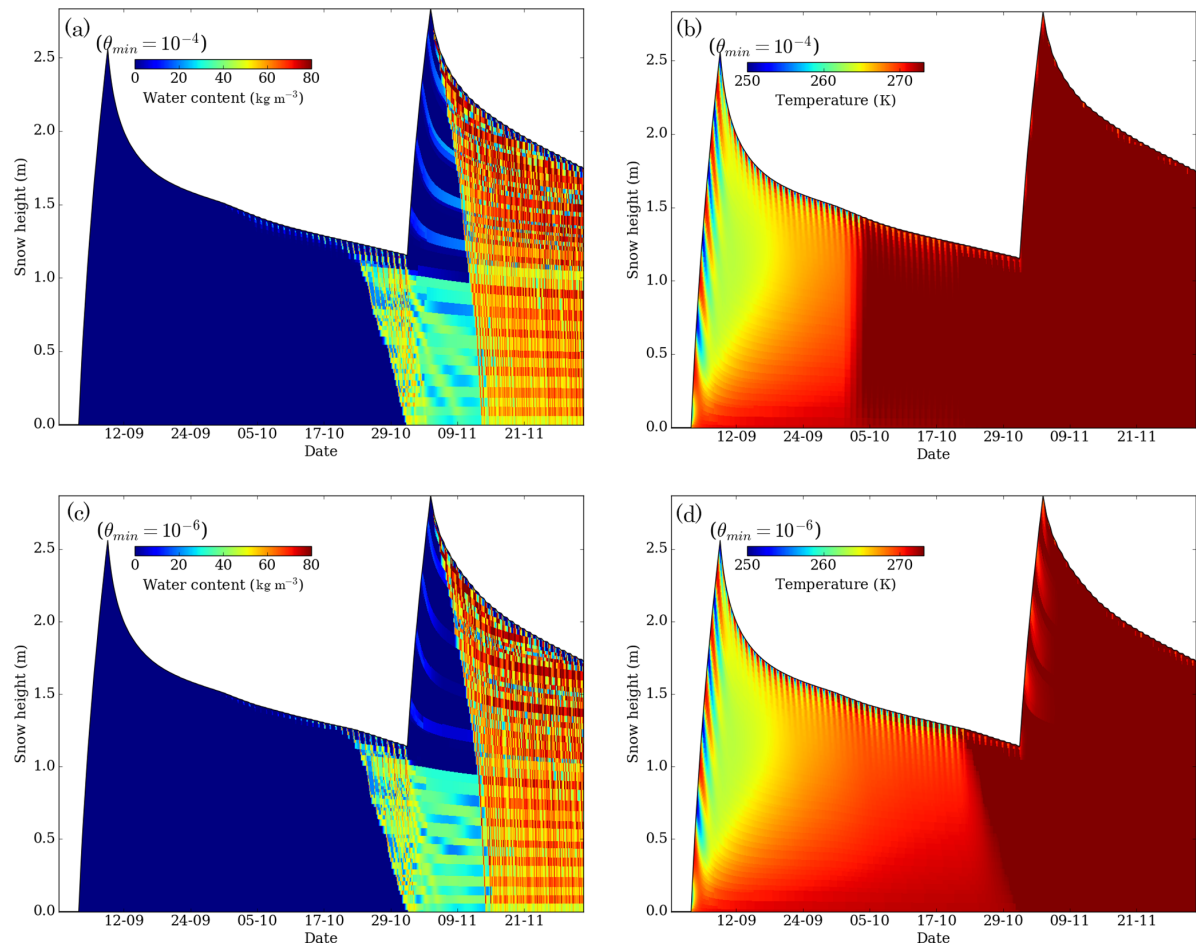

Figure C1. Water percolation and temperature evolution in the simulated data set with different prewetting amounts; plots use the freeflowing bottom boundary with prewetting set to $\theta_{\min }=10^{-4}$ for (a) water content and (b) temperature and $\theta_{\min }=10^{-6}$ for (c) water content and (d) temperature. 
Competing interests. The authors declare that they have no conflict of interest.

Acknowledgements. We thank the NIFS project (www.naturfare. no) for the financial support of this study. We would like to thank Nander Wever and one anonymous referee for the useful comments which improved the quality of this paper. IGE and CNRM/CEN are part of LabEX OSUG@2020.

Edited by: Jeremy Fyke

Reviewed by: Nander Wever and one anonymous referee

\section{References}

Adachia, S., Yamaguchia, S., Ozekib, T., and Kosec, K.: Hysteresis in the water retention curve of snow measured using an MRI system, available at: http://arc.lib.montana.edu/snow-science/ objects/issw-2012-918-922.pdf (last access: 6 July 2016), 2012.

Ambach, W. and Howorka, F.: Avalanche Activity and Free Water Content of Snow at Obergurgl (1980 m a.s.l., Spring 1962), Assoc. Int. Hydrol. Sci., 65-72, 1966.

Avanzi, F., Hirashima, H., Yamaguchi, S., Katsushima, T., and De Michele, C.: Observations of capillary barriers and preferential flow in layered snow during cold laboratory experiments, The Cryosphere, 10, 2013-2026, https://doi.org/10.5194/tc-10-20132016, 2016.

Bengtsson, L.: Percolation of meltwater through a snowpack, Cold Reg. Sci. Technol., 6, 73-81, doi10.1016/0165-232X(82)900465, 1982.

Birkeland, K. W., Hansen, K. J., and Brown, R. L.: The Spatial Variability of Snow Resistance on Potential Avalanche Slopes, J. Glaciol., 41, 183-190, 1995.

Brun, E. and Rey, L.: Field study on snow mechanical properties with special regard to liquid water content, IAHS Publ., 162, 183-193, 1987.

Brun, E., Martin, E., Simon, V., Gendre, C., and Coleou, C.: An Energy and Mass Model of Snow Cover Suitable for Operational Avalanche Forecasting, J. Glaciol., 35, 333-342, https://doi.org/10.1017/S0022143000009254, 1989.

Calonne, N., Geindreau, C., Flin, F., Morin, S., Lesaffre, B., Rolland du Roscoat, S., and Charrier, P.: 3-D image-based numerical computations of snow permeability: links to specific surface area, density, and microstructural anisotropy, The Cryosphere, 6 , 939-951, https://doi.org/10.5194/tc-6-939-2012, 2012.

Carmagnola, C. M., Morin, S., Lafaysse, M., Domine, F., Lesaffre, B., Lejeune, Y., Picard, G., and Arnaud, L.: Implementation and evaluation of prognostic representations of the optical diameter of snow in the SURFEX/ISBA-Crocus detailed snowpack model, The Cryosphere, 8, 417-437, https://doi.org/10.5194/tc8-417-2014, 2014.

Celia, M. A., Bouloutas, E. T., and Zarba, R. L.: A general mass-conservative numerical solution for the unsaturated flow equation, Water Resour. Res., 26, 1483-1496, https://doi.org/10.1029/WR026i007p01483, 1990.

Colbeck, S. C.: A theory of water percolation in snow, J. Glaciol., 11, 369-385, https://doi.org/10.1017/S0022143000022346, 1972.
Colbeck, S. C.: The capillary effects on water percolation in homogeneous snow, J. Glaciol., 13, 85-97, 1974a.

Colbeck, S. C.: Water flow through snow overlying an impermeable boundary, Water Resour. Res., 10, 119-123, https://doi.org/10.1029/WR010i001p00119, 1974b.

Colbeck, S. C.: A theory for water flow through a layered snowpack, Water Resour. Res., 11, 261-266, https://doi.org/10.1029/WR011i002p00261, 1975.

Colbeck, S. C.: An analysis of water flow in dry snow, Water Resour. Res., 12, 523-527, https://doi.org/10.1029/WR012i003p00523, 1976.

Colbeck, S. C.: Water flow through heterogeneous snow, Cold Reg. Sci. Technol., 1, 37-45, https://doi.org/10.1016/0165232X(79)90017-X, 1979.

Coleou, C. and Lesaffre, B.: Irreducible water saturation in snow: experimental results in a cold laboratory, Ann. Glaciol., 26, 6468, 1998.

Daanen, R. P. and Nieber, J. L.: Model for coupled liquid water flow and heat transport with phase change in a snowpack, J. Cold Reg. Eng., 23, 43-68, https://doi.org/10.1061/(ASCE)0887381X(2009)23:2(43), 2009.

Denoth, A.: The pendular-funicular liquid transition in snow, J. Glaciol., 25, 93-98, 1980.

Denoth, A.: "The pendular-funicular liquid transition and snow metamorphism, J. Glaciol., 28, 357-364, 1982.

Durand, Y., Laternser, M., Giraud, G., Etchevers, P., Lesaffre, B. and Mérindol, L.: Reanalysis of $44 \mathrm{yr}$ of climate in the French Alps (1958-2002): methodology, model validation, climatology, and trends for air temperature and precipitation, J. Appl. Meteorol. Clim., 48, 429-449, https://doi.org/10.1175/2008JAMC1808.1, 2009.

Etchevers, P., Martin, E., Brown, R., Fierz, C., Lejeune, Y., Bazile, E., Boone, A., Dai, Y., Essery, R., Fernandez, A., Gusev, Y., Jordan, R., Koren, V., Kowalczyk, E., Nasonova, N. O., Pyles, R. D., Schlosser, A., Shmakin, A. B., Smirnova, T. G., Strasser, U., Verseghy, D., Yamazaki, T., and Yang, Z.: Validation of the energy budget of an alpine snowpack simulated by several snow models (SnowMIP project), Ann. Glaciol., 38, 150-158, doi:10.3189/172756404781814825, 2004.

Hartman, H. and Borgeson, L. E.: Wet slab instability at the Arapahoe Basin ski area, in Proceedings, International Snow Science Workshop: Whistler, BC, Canada, 163-169, available at: http:// arc.lib.montana.edu/snow-science/objects/P_8021.pdf (last access: 24 January 2017), 2008.

Hirashima, H., Yamaguchi, S., Sato, A., and Lehning, M.: Numerical modeling of liquid water movement through layered snow based on new measurements of the water retention curve, Cold Reg. Sci. Technol., 64, 94-103, https://doi.org/10.1016/j.coldregions.2010.09.003, 2010.

Hirashima, H., Yamaguchi, S., and Katsushima, T.: A multidimensional water transport model to reproduce preferential flow in the snowpack, Cold Reg. Sci. Technol., 108, 80-90, https://doi.org/10.1016/j.coldregions.2014.09.004, 2014.

Illangasekare, T. H., Walter, R. J., Meier, M. F., and Pfeffer, W. T.: Modeling of meltwater infiltration in subfreezing snow, Water Resour. Res., 26, 1001-1012, https://doi.org/10.1029/WR026i005p01001, 1990. 
Jordan, P.: Meltwater movement in a deep snowpack: 2. Simulation model, Water Resour. Res., 19, 979-985, https://doi.org/10.1029/WR019i004p00979, 1983.

Jordan, R.: Effects of Capillary Discontinuities on Water Flow Retention in Layered Snow covers, Def. Sci. J., 45, 79-91, 1995.

Jordan, R. E., Hardy, J. P., Perron, F. E., and Fisk, D. J.: Air permeability and capillary rise as measures of the pore structure of snow: an experimental and theoretical study, Hydrol. Process., 13, 1733-1753, https://doi.org/10.1002/(SICI)10991085(199909)13:12/13<1733::AID-HYP863>3.0.CO;2-2, 1999.

Katsushima, T., Kumakura, T., and Takeuchi, Y.: A multiple snow layer model including a parameterization of vertical water channel process in snowpack, Cold Reg. Sci. Technol., 59, 143-151, https://doi.org/10.1016/j.coldregions.2009.09.002, 2009.

Lafaysse, M., Cluzet, B., Dumont, M., Lejeune, Y., Vionnet, V., and Morin, S.: A multiphysical ensemble system of numerical snow modelling, The Cryosphere, 11, 1173-1198, https://doi.org/10.5194/tc-11-1173-2017, 2017.

Leroux, N. R. and Pomeroy J. W.: Modelling capillary hysteresis effects on preferential flow through melting and cold layered snowpacks, Adv. Water Resour., 107, 250-264, https://doi.org/10.1016/j.advwatres.2017.06.024, 2017.

Machguth, H., MacFerrin, M., As, D. van, Box, J. E., Charalampidis, C., Colgan, W., Fausto, R. S., Meijer, H. A. J., Mosley-Thompson, E., and van de Wal, R. S. W.: Greenland meltwater storage in firn limited by nearsurface ice formation, Nat. Clim. Change, 6, 390-393, https://doi.org/10.1038/nclimate2899, 2016.

Marsh, P.: Water flux in melting snow covers, Adv. Porous media, 1, 61-124, 1991.

Marsh, P. and Woo, M.-K.: Wetting front advance and freezing of meltwater within a snow cover: 2. A simulation model, Water Resour. Res., 20, 1865-1874, https://doi.org/10.1029/WR020i012p01865, 1984.

McClung, D. and Schaerer, P. A.: The avalanche handbook, The Mountaineers Books, The Mountaineers books, Seattle, WA, USA, 2006.

Morin, S., Lejeune, Y., Lesaffre, B., Panel, J.-M., Poncet, D., David, P., and Sudul, M.: An 18-yr long (1993-2011) snow and meteorological dataset from a mid-altitude mountain site (Col de Porte, France, $1325 \mathrm{~m}$ alt.) for driving and evaluating snowpack models, Earth Syst. Sci. Data, 4, 13-21, https://doi.org/10.5194/essd4-13-2012, 2012.

Noilhan, J. and Mahfouf, J.-F.: The ISBA land surface parameterisation scheme, Global Planet. Change, 13, 145-159, https://doi.org/10.1016/0921-8181(95)00043-7, 1996.

NVE: Filefjell data set, https://doi.org/10.11582/2017.00010, 2017a.

NVE: Simulated data set (neverland), https://doi.org/10.11582/2017.00009, 2017b.

Paniconi, C. and Putti, M.: A Comparison of Picard and Newton Iteration in the Numerical Solution of Multidimensional Variably Saturated Flow Problems, Water Resour. Res., 30, 3357-3374, 1994.

Philip, J. R.: The Growth of Disturbances in Unstable Infiltration Flows, Soil Sci. Soc. Am. J., 39, 1049-1053, https://doi.org/10.2136/sssaj1975.03615995003900060014x, 1975.
Riche, F. and Schneebeli, M.: Thermal conductivity of snow measured by three independent methods and anisotropy considerations, The Cryosphere, 7, 217-227, https://doi.org/10.5194/tc-7217-2013, 2013.

Schneebeli, M.: Development and stability of preferential flow paths in a layered snowpack, IAHS Publ.-Ser. Proc. Rep.-Intern Assoc Hydrol. Sci., 228, 89-96, 1995.

Shimizu, H.: Air permeability of deposited snow, Contrib. Inst. Low Temp. Sci. A, 22, 1-32, 1970.

Singh, P., Spitzbart, G., Hübl, H., and Weinmeister, H. W.: Hydrological response of snowpack under rain-on-snow events: a field study, J. Hydrol., 202, 1-20, https://doi.org/10.1016/S00221694(97)00004-8, 1997.

Sturm, M., Holmgren, J., König, M., and Morris, K.: The thermal conductivity of seasonal snow, J. Glaciol., 43, 26-41, 1997.

Szymkiewicz, A.: Approximation of internodal conductivities in numerical simulation of one-dimensional infiltration, drainage, and capillary rise in unsaturated soils, Water Resour. Res., 45, W10403, https://doi.org/10.1029/2008WR007654, 2009.

Techel, F. and Pielmeier, C.: Wet snow diurnal evolution and stability assessment, in International Snow Science Workshop ISSW, Davos, Switzerland, 256-261, 2009.

Techel, F. and Pielmeier, C.: Point observations of liquid water content in wet snow - investigating methodical, spatial and temporal aspects, The Cryosphere, 5, 405-418, https://doi.org/10.5194/tc5-405-2011, 2011.

Van Genuchten, M. T.: A closed-form equation for predicting the hydraulic conductivity of unsaturated soils, Soil Sci. Soc. Am. J., 44, 892-898, https://doi.org/10.2136/sssaj1980.03615995004400050002x, 1980.

Vera Valero, C., Wever, N., Bühler, Y., Stoffel, L., Margreth, S., and Bartelt, P.: Modelling wet snow avalanche runout to assess road safety at a high-altitude mine in the central Andes, Nat. Hazards Earth Syst. Sci., 16, 2303-2323, https://doi.org/10.5194/nhess16-2303-2016, 2016.

Vernay, M., Lafaysse, M., Mérindol, L., Giraud, G., and Morin, S.: Ensemble forecasting of snowpack conditions and avalanche hazard, Cold Reg. Sci. Technol., 120, 251-262, https://doi.org/10.1016/j.coldregions.2015.04.010, 2015.

Vionnet, V., Brun, E., Morin, S., Boone, A., Faroux, S., Le Moigne, P., Martin, E., and Willemet, J.-M.: The detailed snowpack scheme Crocus and its implementation in SURFEX v7.2, Geosci. Model Dev., 5, 773-791, https://doi.org/10.5194/gmd-5773-2012, 2012.

Wakahama, G.: The role of meltwater in densification processes of snow and firn, Int. Assoc. Hydrol. Sci. Publ., 114, 66-72, 1975.

Wankiewicz, A.: Water pressure in ripe snowpacks, Water Resour. Res., 14, 593-600, https://doi.org/10.1029/WR014i004p00593, 1978.

Wever, N., Fierz, C., Mitterer, C., Hirashima, H., and Lehning, M.: Solving Richards Equation for snow improves snowpack meltwater runoff estimations in detailed multi-layer snowpack model, The Cryosphere, 8, 257-274, https://doi.org/10.5194/tc-8-2572014, 2014.

Wever, N., Schmid, L., Heilig, A., Eisen, O., Fierz, C., and Lehning, M.: Verification of the multi-layer SNOWPACK model with different water transport schemes, The Cryosphere, 9, 2271-2293, https://doi.org/10.5194/tc-9-2271-2015, 2015. 
Wever, N., Vera Valero, C., and Fierz, C.: Assessing wet snow avalanche activity using detailed physics based snowpack simulations, Geophys. Res. Lett., 43, 5732-5740, https://doi.org/10.1002/2016GL068428, 2016a.

Wever, N., Würzer, S., Fierz, C., and Lehning, M.: Simulating ice layer formation under the presence of preferential flow in layered snowpacks, The Cryosphere, 10, 2731-2744, https://doi.org/10.5194/tc-10-2731-2016, 2016b.

Williams, M. W., Erickson, T. A., and Petrzelka, J. L.: Visualizing meltwater flow through snow at the centimetre-to-metre scale using a snow guillotine, Hydrol. Process., 24, 2098-2110, https://doi.org/10.1002/hyp.7630, 2010.
Yamaguchi, S., Katsushima, T., Sato, A., and $\mathrm{Ku}-$ makura, T.: Water retention curve of snow with different grain sizes, Cold Reg. Sci. Technol., 64, 87-93, https://doi.org/10.1016/j.coldregions.2010.05.008, 2010.

Yamaguchi, S., Watanabe, K., Katsushima, T., Sato, A., and Kumakura, T.: Dependence of the water retention curve of snow on snow characteristics, Ann. Glaciol., 53, 6-12, https://doi.org/10.3189/2012AoG61A001, 2012. 